\title{
Syntactic development in children with hemispherectomy: The I-, D-, and C-systems
}

\author{
Susan Curtiss ${ }^{\mathrm{a}, *}$, Jeannette Schaeffer ${ }^{\mathrm{b}}$ \\ a Department of Linguistics, University of California at Los Angeles, 405 Hilgard Ave., Los Angeles, CA 90095-1543, USA \\ ${ }^{\mathrm{b}}$ Department of Foreign Literatures and Linguistics, Ben-Gurion University of the Negev, Israel
}

Accepted 15 December 2004

Available online 10 February 2005

\begin{abstract}
This study reports on functional morpheme (I, D, and C) production in the spontaneous speech of five pairs of children who have undergone hemispherectomy, matching each pair for etiology and age at symptom onset, surgery, and testing. Our results show that following left hemispherectomy $(\mathrm{LH})$, children evidence a greater error rate in the use of functional category elements than their right hemispherectomy $(\mathrm{RH})$ counterparts. Nevertheless, error rates are surprisingly low and comparable across groups. We interpret these results as (a) weak empirical evidence for a left hemisphere advantage in acquisition of functional structure, (b) strong support that functional structure is a property of all human grammars, and (c) strong support that each isolated developing hemisphere has the potential to acquire a grammar embodying and constrained by highly specific structural principles defining human language.
\end{abstract}

(C) 2005 Elsevier Inc. All rights reserved.

Keywords: Language; Grammar; Hemispherectomy; Functional categories; Acquisition; Syntactic development

\section{Introduction}

Linguistic theory, acquisition theory, and neurolinguistic theory are all concerned with determining the characteristics and properties of the human biological endowment for grammar and grammar acquisition. In this study we examine a fundamental aspect of grammar in the grammatical development of children who have undergone hemispherectomy to control intractable epilepsy. In doing so, our first objective is to investigate the grammars of children who have undergone hemispherectomy as a way to gain insight into the potential of each isolated, developing hemisphere to subserve grammatical development. Our second objective is to provide evidence regarding whether and/or when the grammars of these children include the fundamental

\footnotetext{
* Corresponding author.

E-mail addresses: scurtiss@ucla.edu (S. Curtiss), jschaef@bgu.ac.il (J. Schaeffer).
}

property of adult grammars commonly referred to as functional category systems; namely, the set of morphological properties or features which play a crucial role in defining well-formed syntactic structures. ${ }^{1}$

The focus of this paper is on the functional categories related to verbal inflection (including modals and auxiliaries), determiners, and complementizers/relative pronouns/WH-elements - traditionally referred to as I, D, and $\mathrm{C}$, respectively. We will examine whether and how fully the grammars of children who have undergone right or left hemispherectomy embody the structural elements of these functional category systems. Our third objective is to ascertain whether the isolated left hemisphere (LH), the predominant neural substrate for grammar in the vast majority of humans, shows an advantage over the isolated right hemisphere $(\mathrm{RH})$ in the development of I-, D-, and C-system structures.

\footnotetext{
${ }^{1}$ Functional category elements correspond roughly with those termed "closed class items".
} 
There are thus three objectives and two related sets of issues involved in this work: the neurolinguistic questions regarding the capacity of each isolated hemisphere to subserve grammatical development and the theoretical acquisition issues regarding the fundamental principles operative in grammatical development. Specifically, we refer to whether the functional category systems, or the relevant sets of morphological features, are part of Universal Grammar and are therefore part of every natural grammar, child or adult, impaired or non-impaired. We turn first to the neurolinguistic questions and issues.

\section{Neurolinguistic questions and issues}

There is an enormous literature pertinent to the linguistic and neurolinguistic issues at play, which for the sake of space we summarize here in broad strokes. The literature on the representation and processing of grammar in the adult brain paints a rather consistent picture. Whether considering clinical or experimental, including imaging studies of spoken or sign language, it is the left cerebral hemisphere that is specialized for the representation and processing of grammar in the adult. ${ }^{2}$ Some experimental and imaging results implicate several regions activated in concert in response to linguistic stimuli but do not change the basic picture of a left hemisphere specialization for human grammars, and in fact are beginning to confirm and validate the localization of phonology and morphosyntax to specific areas within the left hemisphere (see Binder \& Price, 2001; Hickok, Love-Geffen, \& Klima, 2002 for relevant summaries).

With respect to language development, however, the picture is less clear. Neurobiological and neuroanatomical evidence, even during gestation, support the position that the left hemisphere is "prepotent", preprogrammed, as it were, to mediate grammar and its development (e.g. Gallagher \& Watkin, 1997; Molfese \& Segalowitz, 1988; Scheibel, 1993; Witelson, 1982 among others). Event Related Potential (ERP) studies of normal children in early stages of overt lexical acquisition and clinical studies of children with unilateral lesions lend support to the view that the left hemisphere is prepotent for language (Aram, 1988, 1999; Aram \& Eisele, 1992; Cohen, 1992; Mills, Coffey-Corina, \& Neville, 1994; Molfese, 1990; Molfese \& Molfese, 1986, among others). However, some recent work suggests that language development may be impaired after damage to either hemisphere (Bates,

\footnotetext{
${ }^{2}$ A number of recent studies implicate the right hemisphere in syntactic processing of sign language, in particular in the processing of spatialized syntax. However, these studies may reflect the panoply of areas activated during syntactic processing rather than the areas crucial for the processing of syntax. Moreover, none of these studies indicate a right hemisphere specialization either for morpho-syntax or for grammar in toto-phonology, morphology and syntax, or the syntax-semantics interface and the syntax-phonetic form interface.
}

1999; Bates, Thal, \& Janowsky, 1992, 1999; Stark, Bleile, Brandt, Freeman, \& Vining, 1995; Thal, 1998), and that the right hemisphere may play some key role in the early stages of acquisition (Curtiss \& de Bode, 1998, 2003; Curtiss, de Bode, \& Mathern, 2001; Locke, 1997). Imaging studies present inconsistent findings (e.g., Caplan, 2000; Hickok, 2000), which are in any event, difficult to interpret at this point in the state of the art.

Thus, the representation and processing of grammar in the brain, especially in the immature brain, is not a clear-cut or simple matter. In particular, key questions remain regarding the potential of the right hemisphere to subserve grammar acquisition beyond the early stages and the role it may play in grammatical development even under normal circumstances.

The nature and degree of the linguistic impairment reported in acquired aphasia following focal lesions in children is rather variable, and the neurological mechanism for the (re)acquisition of language by children with focal damage remains a matter of speculation. It is unknown whether impaired performance in these cases reflects the best efforts of the damaged left hemisphere, the right hemisphere, or some combination of both. ${ }^{3}$ The potential of the right hemisphere to serve as the substrate for the acquisition of grammar, therefore, perhaps is best determined by the study of grammatical development subsequent to hemispherectomy.

Regarding the effect of side of resection and subsequent grammatical development the literature reports conflicting findings. Many studies of children who have undergone hemispherectomy report greater impairment with respect to grammatical development after left hemispherectomy, including morphosyntactic comprehension, production, and grammaticality judgments as well as reading, writing, and spelling (Boatman et al., 1999; Curtiss \& Schaeffer, 1997; Day \& Ulatowska, 1979; Dennis, 1980a, 1980b; Dennis \& Kohn, 1975; Dennis \& Whitaker, 1976; Ogden, 1996; Patterson, Vargha-Khadem, \& Polkey, 1989; Stark \& McGregor, 1997; Stark et al., 1995; Vargha-Khadem \& Polkey, 1992). Other studies report rich grammatical development after resection of either hemisphere (Mariotti, Iuvone, Torrioli, \& Silveri, 1998; Ogden, 1988; Vargha-Khadem et al., 1997; Vargha-Khadem \& Mishkin, 1997; Verity et al., 1982).

In keeping with these latter findings, in previous work Curtiss and de Bode have reported that side of resection is not the crucial factor in determining linguistic outcomes following pediatric hemispherectomy (Curtiss

\footnotetext{
${ }^{3}$ In the modal brain, the right hemisphere is widely assumed to mediate visual and spatial cognition (e.g., spatial rotation, facial recognition, and wholistic perception) as well as para-linguistic phenomena, such as emotional prosody, humor, and metaphor (cf. Benson \& Zaidel and references, therein; Blake, 2003; Brownell, Michel, Powelson, \& Garndern, 1983; Coulson, in press; Pell, 1999; Shammi \& Stuss, 1999).
} 
$\&$ de Bode, 1999, 2003; Curtiss et al., 2001). In examining the relation between side of surgery and language outcome, only older age at surgery and right-sided resection showed a robust statistical relation. This was interpreted to reflect the fact that after early childhood, the left hemisphere's specialization for language will have become well-established. Ergo, "late" right-side resection, which occurs almost exclusively in cases of acquired pathologies such as Rasmussen's Encephalitis (RE), would have little impact either on language acquisition up to the point of disease onset or on the left hemisphere's mediation of language following hemispherectomy. Curtiss and de Bode have argued that it is etiology that is the crucial predictive factor vis a vis linguistic outcome. Developmental etiologies, especially those involving cortical dysplasia (CD), such as hemimegalencephaly or multi-lobar CD, result in significantly poorer language outcomes (e.g., little or no language development) in contrast to acquired etiologies, such as Rasmussen's Encephalitis (see also Jonas et al., 2004). Moreover, according to the model they propose, etiology becomes the umbrella under which other clinical factors must be considered.

Notwithstanding the predictive power of this proposal for accounting for their own and others' findings with regard to language outcomes following hemispherectomy in children, we wanted to examine whether side of resection would be predictive, if we factor in etiology. The central neurolinguistic question our paper addresses, therefore, is the following: Controlling for etiology, will left hemispherectomy result in poorer grammatical development than right hemispherectomy? More specifically, will the LH (left hemispherectomy) evidence better acquisition of the functional category systems - the core of clausal structure - than the isolated right hemisphere?

\section{Theoretical acquisition issues}

Our second objective is to examine the language development of each isolated developing hemisphere for evidence with respect to whether each hemisphere constructs a normal grammar, embodying the principles of UG. To address this objective, we will examine the status of functional categories in the grammars of our subjects to determine whether and/or when their grammars embody the structural elements that comprise the I- (e.g., auxiliaries, tense), D- (e.g., articles, plural markers), and C-(e.g., complementizers, relative pronouns) systems (see Section 4 for theoretical details).

A longstanding controversy in acquisition theory concerns whether or not the early grammars of children contain only lexical categories, i.e., are pre-functional and develop functional category structures and their projections only at later points in syntactic development (cf. Guilfoyle \& Noonan, 1989; Lebeaux, 1988; Platzack, 1992; Radford, 1988, 1990, 1994; Wilson, 2003), or whether even early grammars contain functional categories and thus project essentially adult clausal structures (cf. Borer \& Rohrbacher, 2003; Harris \& Wexler, 1996; Hoekstra \& Hyams, 1998; Hyams, 1992, 1996, 1999, 2001; Poeppel \& Wexler, 1993; Verrips \& Weissenborn, 1992, among others). If, upon examining the grammars of the subjects of our study who are pair-wise matched for etiology, we find direct, overt functional structure more fully realized in the children after right hemispherectomy, we will have evidence that the LH's predisposition for grammar is difficult to overcome, even in the developing brain. If, however, we find direct, overt functional structure in our subjects regardless of side of surgery, we will obtain powerful evidence that such functional structure is a property of all human grammars, child or adult, impaired or non-impaired and that each isolated developing hemisphere has the potential to acquire a normal grammar, that is, one embodying and constrained by highly specific structural principles defining human language.

We now turn to the theoretical framework that guides our work.

\section{Theoretical framework}

\subsection{Introduction}

The theoretical framework we adopt is grounded in Chomsky's (1981) "Principles and Parameters" theory, which has more recently evolved into the so-called "Minimalist Program" (Chomsky, 1995, 2000). The Minimalist Program holds the promise of a syntactic theory in which cross-linguistic variation is restricted to morphological properties of the lexicon. This means that linguistic variation falls out of just the morphological properties (abstract and concrete) of the lexicon (Borer, 1984). In this model, there are two central components: $\mathrm{C}_{\mathrm{HL}}$, a computational system for human language, which is presumed to be invariant across languages, and a lexicon, to which the idiosyncratic differences observed across languages are attributed. This implies that the notion of phrase structure does not vary across languages; and surface differences in word order relate only to the rearrangement of elements in the syntactic tree as the result of movement operations, triggered by lexically encoded morphological features.

Thus, syntactic movement is driven by "feature checking": the lexically encoded morphological features must be checked in their appropriate functional nodes in the syntactic tree. If they are not already located (i.e., basegenerated) in the relevant functional node, they have to move there. This can be done either overtly (at $\mathrm{PF}=$ "Phonetic Form") or covertly (at LF = "Logical 
Form"). ${ }^{4}$ As noted in the introduction, morphemes triggering movement to or residing in functional positions, i.e., functional morphemes, are the focus of our study.

\subsection{The I-system}

The set of I-system functional morphemes includes features such as person, number, gender, and case (among other morphemes - see below). These features, except for gender, play a crucial role in our study. ${ }^{5}$ The inflection on English finite verbs expresses person and number, in agreement with the person and number of the subject. In addition, the English subject bears nominative case. In order for the person/number features of both the finite verb and the subject to be checked, they need to move to their appropriate functional nodes, which form a "spec-head" configuration (as will be exemplified below). The nominative case of the subject is checked in the specifier of a functional projection as well.

In the latest versions of the Minimalist Program person/number/gender agreement as well as tense and nominative case checking takes place in TP. However, we follow Pollock (1989) and Chomsky (1991) in assuming that there is a split IP and thus a separate AGRSP and a TP. ${ }^{6}$ Nonetheless, for reasons of simplicity, we will refer to AGRSP and TP together as the "I-system" throughout the paper. An illustration of spec-head agreement between the subject (she) and the verb (goes) in AGRSP is given in (1):

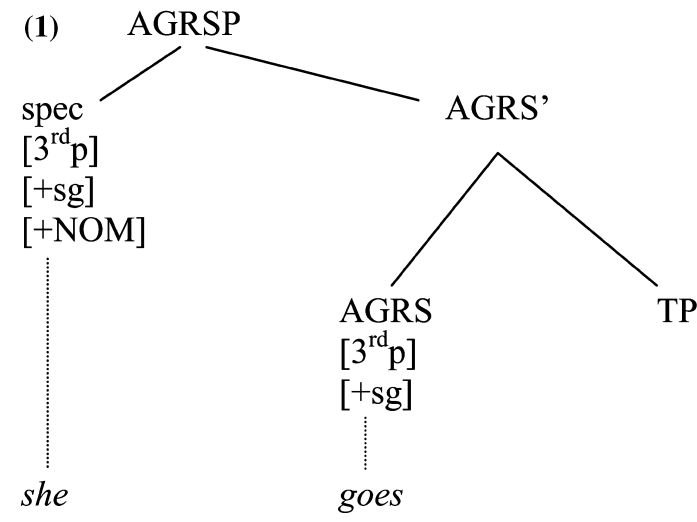

Besides person, number, and case there are other morphological features related to the verb, such as tense, and aspect. The tense property of the verb is checked in the functional head $\mathrm{T}$. Thus, the finite verb moves from

\footnotetext{
${ }^{4}$ Or, more strictly speaking, at the syntax-PF interface or the syntax-LF interface.

${ }^{5}$ This is merely an artefact of English, which does not overtly encode grammatical gender.

${ }^{6}$ By including those functional projections we used for our analysis, we are not making a theoretical claim that the internal structure of IP is exactly what we outline in our paper.
}

its base-generated V-position to $\mathrm{T}$. Once tense is checked, the verb moves on to AGRS. This is illustrated in (2). ${ }^{7}$ We also assume and include an AGROP (Agreement Object Phrase) and will elaborate on this functional projection below.

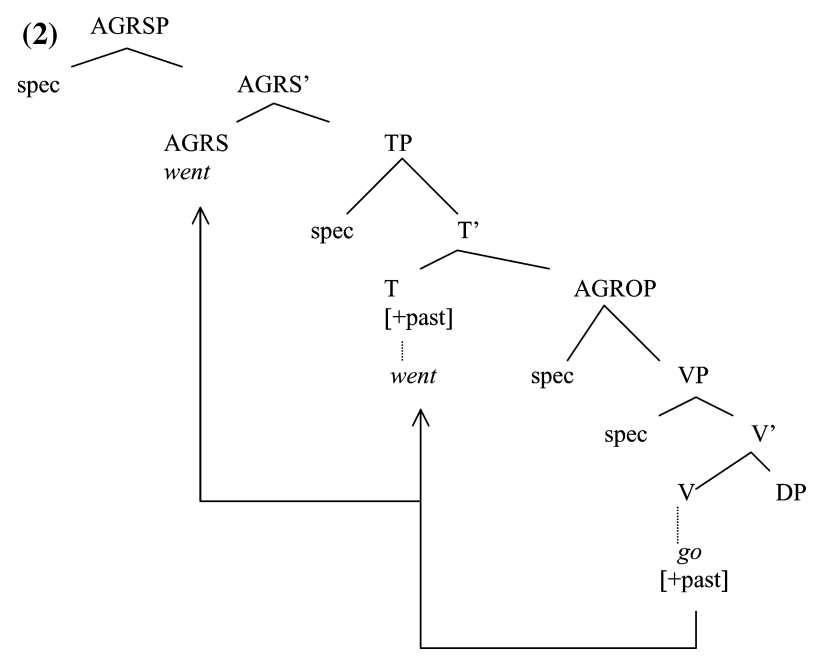

In the same spirit, aspectual morphemes, such as progressive - ing as in Mary is kissing, and perfective - en as in Mary has eaten are hosted and checked in the functional head AGRO (Agreement Object Phrase). If the sentence contains an object, the object is assumed to move to spec AGROP in order to check its accusative case. ${ }^{8}$ Furthermore, object agreement with the past participle (in languages such as Italian), takes place in AGROP. The structure of AGROP and the English examples are illustrated in (3):

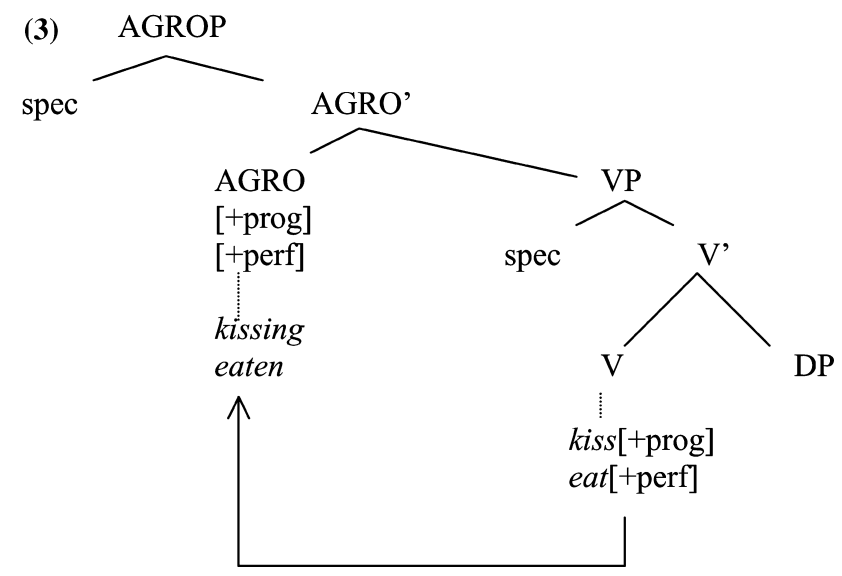

\footnotetext{
${ }^{7}$ Languages vary as to whether tense and agreement checking take place overtly or covertly (at LF). English is a language in which checking of tense and agreement occurs at LF, i.e., covertly. But see Johnson (1986), Campbell (1991), and Fox and Pesetsky (2003) for arguments that in English, tense and agreement checking occurs at PF; i.e., overtly.

${ }^{8}$ Again, languages vary as to whether the object moves to spec AGROP overtly or at LF. In English, this takes place at LF.
} 
Because of the parallel between AGRO and AGRS, and because AGRO often interacts with T and AGRS (progressive constructions appear with inflected finite forms of the auxiliary be and participles occur with inflected finite forms of the auxiliary have) we included AGRO in the set of functional morphemes we examined.

\subsection{The D-system}

The functional category $\mathrm{D}$ is designated to check nominal features (such as definiteness, number, and gender). For example, the definite article the is hosted by $\mathrm{D}$, where it checks its definiteness feature. Furthermore, a noun can move to D in order to check its features (such as proper names), or a possessive pronoun can occupy D (Longobardi, 1994). Besides the DP layer itself, the DP contains another functional layer, namely NumP, which is the functional category responsible for number (singular/plural) checking (Ritter, 1988). The structure of DP we assume for this paper is exemplified in (4):

(4) $\overbrace{\mathrm{D}^{\prime}}^{\mathrm{DP}}$

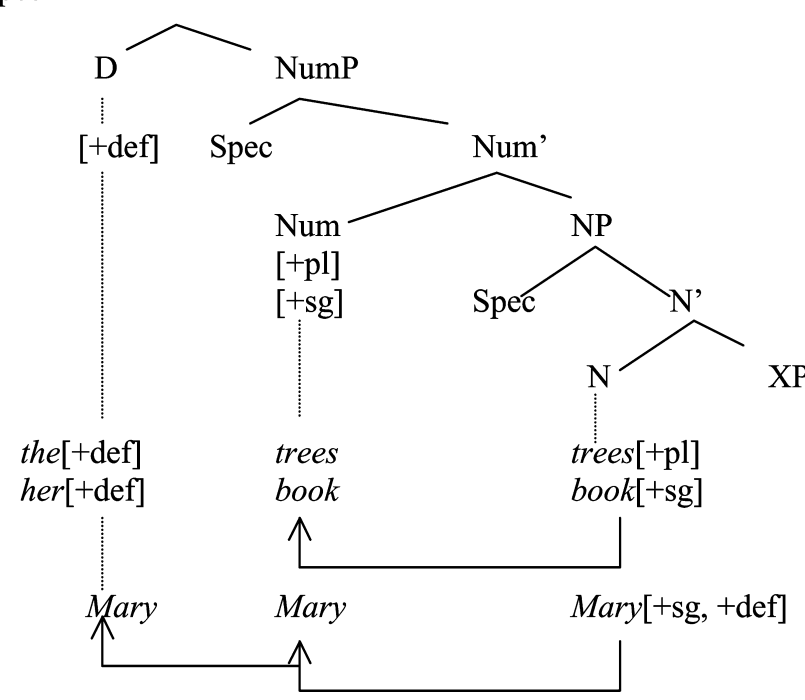

\subsection{The C-system}

Finally, complementizers, WH-elements, relative pronouns, and moved auxiliaries (for interrogative formation) are related to the functional category $\mathrm{C}$. Complementizers and relative pronouns reside in $\mathrm{C}$ itself, whereas $\mathrm{WH}$-elements move to spec $\mathrm{CP}$ in order to check their WH/Question feature. Furthermore, auxiliaries move from AGRS to $\mathrm{C}$ in interrogatives, where they enter a spec-head configuration with the WH/Question feature in spec CP. ${ }^{9}$

In sum, we assume the following functional categories: C, AGRS, T, AGRO, and D. Assuming that the top layer of all sentences is a $\mathrm{CP}$, the complete syntactic tree for a sentence such as What has she eaten? would be as in (5):

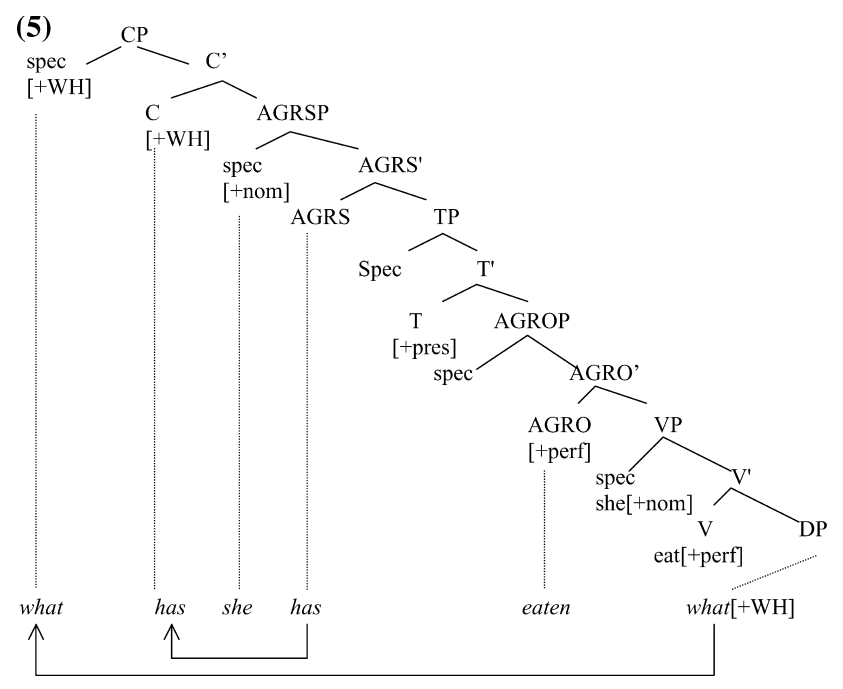

\section{Predictions}

Given the theoretical and evidential background provided in Section 3, we make the following predictions:

1. Controlling for etiology and age, the children who have undergone left hemispherectomy will evidence a greater error rate in use of functional category elements compared to their right hemispherectomy counterparts.

2. The right-hemispherectomized children, those with only a left hemisphere, will develop normal grammars, exhibiting normal developmental patterns with respect to the functional category systems, eventually attaining the adult functional category systems in the target language.

3. Given increasing evidence that early child grammars, normal and abnormal, embody functional categories, even in the course of protracted and impaired linguistic development, the left-hemispherectomied children will, nonetheless, develop grammars which contain the functional categories present in adult English.

\footnotetext{
${ }^{9}$ Similar to Pollock's split I, Rizzi (1997) proposes that C is split into several functional categories as well, including ForceP and TopicP. Although these distinctions are useful, they go beyond the scope of our paper, and therefore we stick to the term $\mathrm{CP}$ for the left periphery of the sentence.
} 


\section{Subjects}

The subjects for the study were 10 children who had undergone hemispherectomy as part of the UCLA Pediatric Surgery Research Program (Cook et al., 2004; Peacock et al., 1996). The children comprised five pairs of children matched as closely as possible for etiology, chronological age (CA) at surgery, and CA at testing. We were hampered in our attempts to make close matches on all these variables by the fact that even with the largest pediatric hemispherectomy series in the world to date, exact matches on each of these variables were not possible. Information on the subjects, their gender, age at symptom onset, age at surgery, age at data collection, etiology, and MLU is presented in Table 1 (age is represented as years;months).

Clinical parameters such as age at symptom onset and age at surgery for comparing the LHG and RHG are not terribly meaningful here, as with one exception, the children with infarcts had perinatal infarcts, while none of the children with RE evidenced symptoms before the age of two years. The age of symptom onset for those with RE ranged between the ages of $2 ; 3$ (RB) and 10;4 (TP). For the sake of completeness, however, we include this information. The children with left hemispherectomy ranged in chronological age (CA) at the time of surgery from $3 ; 6$ to $12 ; 9$, and those with right hemispherectomy, from $3 ; 5$ to $14 ; 0$. The mean age at symptom onset was 3;9 for the left hemispherectomy group (LHG) and 3;0 for the right hemispherectomy group (RHG); mean age at surgery was $7 ; 2$ for the LHG and 7;2 for the RHG. Mean time after surgery at age of testing was 6;4 for the LHG and 2;5 years for the RHG. One of the children in the RHG (JE) was tested less than one month after surgery and subsequently passed away; thus, we had only his one language sample to use in this analysis and are using his data because he was the best match for GG on the parameters most relevant to our study. The large discrepancy across children in the period of time between surgery and the language samples we collected results from the fact that, following surgery, a number of children in our study experienced significant delays before beginning to speak and then producing enough speech for us to analyze. The difference is largely a result of the RHG's being linguistically competent and available for linguistic evaluation far earlier post-surgically than the LHG.

\section{Procedures}

For most of the children, the data used for analysis consisted of transcripts of language samples generated from the Kiddie Formal Thought Disorder Scales (KFTDS) (Caplan, Guthrie, Fish, Tanguay, \& DavidLando, 1989). This is a "Story Game" task consisting of three parts: In the first and third parts each subject listens to an audio-taped story and then is asked to retell the story and answer pre-established, standardized probe questions about the stories heard. In the second part, each child is asked to make up a story about one of several topics: a dream about a friendly ghost, an ostracized little boy, the Incredible Hulk, a witch, a good or bad child, or an unhappy child. The K-FTDS has been used with many different populations including schizophrenic and other epileptic children (e.g., Caplan et al., 1993) and has proved to be an excellent task for generating rich language sample data. One RHG child, MP, did not have sufficiently fluent language for this procedure to be administered, so for her sample we used a naturalistic conversation between one of the authors and the child. Topics covered were favorite games, toys, and her birthday. We included her in the study because she was the best match we had for her LHG counterpart on key parameters for matching. Note that by including MP in our study, however, we are biasing the results against what we hypothesize we will find. Therefore, results supporting our hypotheses will have passed a stronger test than if we had eliminated her.

Table 1

Subject information

\begin{tabular}{|c|c|c|c|c|c|c|c|}
\hline Side of surgery & $\begin{array}{l}\text { Child/sex/file } \\
\text { name }\end{array}$ & MLU & Etiology & $\begin{array}{l}\text { Age at sample } \\
\text { (years; months) }\end{array}$ & $\begin{array}{l}\text { Age at onset } \\
\text { (years; months) }\end{array}$ & $\begin{array}{l}\text { Age at surgery } \\
\text { (years; months) }\end{array}$ & $\begin{array}{l}\text { Mental age } \\
\text { (years; months) }\end{array}$ \\
\hline Left & $\begin{array}{l}1 \mathrm{GG} / \mathrm{male} / \mathrm{gg} 4 \\
2 \mathrm{SM} / \mathrm{female} / \mathrm{sm} 3 \\
3 \mathrm{TP} / \mathrm{male} / \mathrm{tp} 2 \\
4 \mathrm{LT} / \mathrm{female} / \mathrm{lt} 2 \\
5 \mathrm{RB} / \mathrm{male} / \mathrm{rb} 2\end{array}$ & $\begin{array}{l}4.48 \\
5.28 \\
5.54 \\
4.26 \\
3.21\end{array}$ & $\begin{array}{l}\text { Infarct } \\
\text { Infarct } \\
\text { RE } \\
\text { RE } \\
\text { RE }\end{array}$ & $\begin{array}{l}8 ; 0 \\
13 ; 8 \\
15 ; 5 \\
7 ; 11 \\
6 ; 7\end{array}$ & $\begin{array}{l}0 ; 10 \\
\text { Birth } \\
10 ; 4 \\
5 ; 6 \\
2 ; 3\end{array}$ & $\begin{array}{l}6 ; 2 \\
4 ; 0 \\
12 ; 9 \\
6 ; 11 \\
3 ; 6\end{array}$ & $\begin{array}{l}3 ; 1 \\
5 ; 2 \\
10 ; 0 \\
3 ; 10 \\
3 ; 9\end{array}$ \\
\hline Right & $\begin{array}{l}1 \mathrm{JE} / \mathrm{male} / \mathrm{je} 1 \\
2 \mathrm{MP} / \mathrm{female} / \mathrm{mp} 1 \\
3 \mathrm{MC} / \text { female/mc2 } \\
4 \mathrm{BB} / \mathrm{female} / \mathrm{bb} 3 \\
5 \mathrm{MO} / \mathrm{male} / \mathrm{mo} 4\end{array}$ & $\begin{array}{l}3.70 \\
2.0 \\
7.5 \\
7.95 \\
6.65\end{array}$ & $\begin{array}{l}\text { Infarct } \\
\text { Infarct } \\
\text { RE } \\
\text { RE } \\
\text { RE }\end{array}$ & $\begin{array}{l}7 ; 10 \\
13 ; 0 \\
15 ; 8 \\
6 ; 11 \\
6 ; 6\end{array}$ & $\begin{array}{l}4 ; 0 \\
0 ; 2 \\
4 ; 2 \\
4 ; 9 \\
2 ; 1\end{array}$ & $\begin{array}{l}7 ; 9 \\
5 ; 1 \\
14 ; 0 \\
5 ; 8 \\
3 ; 4\end{array}$ & $\begin{array}{l}2 ; 5 \\
2 ; 4 \\
\text { At CA 24: MA: } 17 ; 9^{\mathrm{a}} \\
\text { At CA 6;1: IQ: } 87^{\mathrm{a}} \\
\text { At CA } 9 ; 0: \text { MA: } 6 ; 2^{\mathrm{a}}\end{array}$ \\
\hline
\end{tabular}

${ }^{\text {a }}$ No MA data available for CA at testing. 
The entire task was videotaped and then transcribed by two independent transcribers. Any disagreements in transcription were resolved by the first author's transcription of the section in question. The transcripts were then typed into the CHILDES format (MacWhinney \& Snow, $1985,1990)$ and coded into a scheme, the Grammatical Coding System (GCS), developed by the authors in conjunction with other linguists working on this project (Curtiss, MacSwan, Schaeffer, Kural, \& Sano, 2004). The GCS includes codes for I-system, C-system, and Dsystem structures plus additional closed class morphemes as well as aspects of constituent structure and other syntactic phenomena. Only performance with I-, C-, and Dsystem structures is presented here. The GCS also includes programs for error counts and analysis as well as for calculating MLU. No rote phrases, no utterances that were direct repetitions of the examiner, and no unintelligible utterances were coded. Nine of the transcripts were coded by two independent coders, at least one of whom was one of the authors, and all disagreements were resolved by discussion. Inter-coder reliability was $96 \%$.

\section{The data}

Our criterion for including data as evidence of I, C, and $\mathrm{D}$ was limited to the occurrence of overt, phonetically pronounced morphemes of the functional categories C, AGRS, T, AGRO, and D. Our criterion for labeling functional category errors was the omission in obligatory contexts or incorrect use of the structures involved. The substitution of forms that indicated an ab-

Table 2

I-system instantiations coded

\begin{tabular}{|c|c|c|}
\hline $\begin{array}{l}\text { Functional } \\
\text { category/code }\end{array}$ & $\begin{array}{l}\text { Specific } \\
\text { morpheme(s) }\end{array}$ & Example \\
\hline $\begin{array}{l}\text { spec AGRSP/ } \\
\text { IPROS }\end{array}$ & $\begin{array}{l}\text { Subject pronoun }{ }^{\mathrm{a}} \\
(I, \text { we, he, she, they })\end{array}$ & She is doing a good job \\
\hline AGRS/IAUX & $\begin{array}{l}\text { Auxiliaries } \\
\text { (do, is, has) } \\
\text { Copulas } \\
\text { Modals } \\
\text { (can, must, will...) } \\
\text { (used to, gonna) } \\
\text { (hafta, oughtta, etc.) }\end{array}$ & $\begin{array}{l}\text { He is baking me a } \\
\text { birthday cake } \\
\text { You are funny } \\
\text { She can speak } 11 \\
\text { languages!! } \\
\text { Jean used to be a chemist } \\
\text { I hafta finish this paper }\end{array}$ \\
\hline /IA-s & $\begin{array}{l}\text { Third person } \\
\text { singular }\end{array}$ & Todd signs fluently \\
\hline TENSE/IT-ed & Regular past & $\begin{array}{l}\text { The cop killed the } \\
\text { burglar }\end{array}$ \\
\hline /IT-d & Irregular past & Monica sang well \\
\hline /ITO & Infinitival to & Clara wants to get a job \\
\hline$A G R O /$-en & $\begin{array}{l}\text { Regular past } \\
\text { participle }\end{array}$ & Joe has talked too long. \\
\hline /-n & $\begin{array}{l}\text { Irregular past } \\
\text { participle }\end{array}$ & Jeff has seen this before \\
\hline /-ing & Progressive & Todd is going to class \\
\hline
\end{tabular}

\footnotetext{
${ }^{a}$ Bearing overt nominative case.
}

sence of I, D or C (e.g., use of accusative case pronoun in a nominative case context) were also counted as errors, but substitutions that resulted from the misselection of allomorphs or comprised lexical semantic substitutions (e.g., seen for saw, or before for because) were not counted as I, D or C errors, as the relevant functional projection was still present. In addition to excluding from our analyses functional structures that are phonetically null we did not include structures whose phonetic form is unchanged by case-marking; i.e., subject pronouns you, it, this, and that and expletives it and there. This way, we probably derived conservative estimates of the status of the I, C, and D-systems in our data.

Table 2 presents the set of elements associated with each of the different instantiations of the I-system that we included in our analyses. Tables 3 and 4 provide

Table 3

Sample omission errors for the I-system instantiations coded

\begin{tabular}{|c|c|c|}
\hline $\begin{array}{l}\text { Functional } \\
\text { category/code }\end{array}$ & $\begin{array}{l}\text { Specific } \\
\text { morpheme(s) }\end{array}$ & Example \\
\hline $\begin{array}{l}\text { spec AGRSP/ } \\
\text { IPROS }\end{array}$ & $\begin{array}{l}\text { Subject pronoun }{ }^{\mathrm{a}} \\
(I, \text { we, he, she, they })\end{array}$ & __ is doing a good job \\
\hline AGRS/IAUX & $\begin{array}{l}\text { Auxiliaries } \\
(\text { do, is, has }) \\
\text { Copulas } \\
\text { Modals } \\
(\text { can, must, will...) }\end{array}$ & $\begin{array}{l}\text { He_baking me a } \\
\text { birthday cake } \\
\text { You_funny } \\
\text { She__speak } 11 \\
\text { languages!! }\end{array}$ \\
\hline /IA-s & $\begin{array}{l}\text { Third person } \\
\text { singular }\end{array}$ & Todd sign__fluently \\
\hline TENSE/IT-ed & Regular past & $\begin{array}{l}\text { Yesterday the cop kill } \\
\text { the burglar }\end{array}$ \\
\hline /IT-d & Irregular past & Last night I sing _ well \\
\hline /ITO & Infinitival to & Clara wants__ get a job \\
\hline AGRO/-en & $\begin{array}{l}\text { Regular past } \\
\text { participle }\end{array}$ & Joe has talk_ too long \\
\hline /-n & $\begin{array}{l}\text { Irregular past } \\
\text { participle }\end{array}$ & Jeff has see_t this before \\
\hline /-ing & Progressive & Todd is go__ to class \\
\hline
\end{tabular}

Table 4

Sample incorrect use errors for the I-system instantiations coded

\begin{tabular}{|c|c|c|}
\hline $\begin{array}{l}\text { Functional } \\
\text { category/code }\end{array}$ & $\begin{array}{l}\text { Specific } \\
\text { morpheme(s) }\end{array}$ & Example \\
\hline $\begin{array}{l}\text { spec AGRSP/ } \\
\text { IPROS }\end{array}$ & $\begin{array}{l}\text { Subject pronoun } \\
(I, \text { we, he, she, they) }\end{array}$ & Her is doing a good job \\
\hline AGRES/IAUX & $\begin{array}{l}\text { Auxiliaries } \\
(\text { do, is, has }) \\
\text { Modals } \\
\text { (can, must will...) }\end{array}$ & $\begin{array}{l}\text { He does baking me a } \\
\text { birthday cake } \\
\text { She is speak } 11 \\
\text { languages! }\end{array}$ \\
\hline /IA-s & $\begin{array}{l}\text { Third person } \\
\text { singular }\end{array}$ & Todd signed fluently now \\
\hline TENSE/IT-ed & Regular past & $\begin{array}{l}\text { The cop killeded the } \\
\text { burglar }\end{array}$ \\
\hline
\end{tabular}

${ }^{a}$ Bearing overt nominative case. 
examples of omission errors and incorrect use related to the structures presented in Table 2.

Table 5 presents the set of elements associated with each of the different instantiations of the D-system that we included in our analyses. Tables 6 and 7 provide examples of omission and incorrect use errors related to the structures presented in Table 5 .

Table 5

D-system instantiations coded

\begin{tabular}{|c|c|c|}
\hline Code & Specific morpheme(s) & Example \\
\hline DART & Article (a/the) & The boy saw a plane \\
\hline DPOSD & Possessive determiner & $\begin{array}{l}\text { My car is chasing your } \\
\text { truck }\end{array}$ \\
\hline DPOS & $\begin{array}{l}\text { Independent poss. } \\
\text { pronoun }\end{array}$ & $\begin{array}{l}\text { This book is mine, that } \\
\text { one is yours }\end{array}$ \\
\hline D-s & Possessive morpheme' $s$ & $\begin{array}{l}\text { John's car is chasing my } \\
\text { mother's truck }\end{array}$ \\
\hline DDEM & $\begin{array}{l}\text { Demonstrative } \\
\text { determiners } \\
\text { (this, that, these, those) }\end{array}$ & $\begin{array}{l}\text { These books are on that } \\
\text { table }\end{array}$ \\
\hline DPRO & $\begin{array}{l}\text { Independent dem. } \\
\text { pronoun } \\
\text { (this, that, these, those) }\end{array}$ & I like that \\
\hline DQUA & $\begin{array}{l}\text { Basic quantifier } \\
\text { (some, any, no, every) }\end{array}$ & I saw some students \\
\hline DCAR & $\begin{array}{l}\text { Cardinality quantifier } \\
\text { (many, few, one, two) }\end{array}$ & $\begin{array}{l}\text { There are five people in } \\
\text { this room } \\
\text { She read a few books }\end{array}$ \\
\hline D-plural & $\begin{array}{l}\text { Plural morpheme } \\
(-s,-e n)\end{array}$ & The children saw planes \\
\hline
\end{tabular}

Table 6

Sample omission errors for the D-system instantiations coded

\begin{tabular}{|c|c|c|}
\hline Code & Specific morpheme(s) ${ }^{a}$ & Example \\
\hline DART & Article (a/the) & _ boy saw _ plane \\
\hline DPOSD & Possessive pronoun & $\begin{array}{l}\text { - car is chasing } \\
\text { truck }\end{array}$ \\
\hline DPOS & Independent poss. pronoun & $\begin{array}{l}\text { This book is }, \text { that } \\
\text { one is }\end{array}$ \\
\hline D-'s & Possessive morpheme 's & $\begin{array}{l}\text { John_car is chasing } \\
\text { my mother_truck }\end{array}$ \\
\hline DDEM & Demonstrative determiner & $\begin{array}{l}\text { books are on } \\
\text { table }\end{array}$ \\
\hline DPRO & Independent dem. pronoun & I like__ \\
\hline DQUA & $\begin{array}{l}\text { Quantifier } \\
\text { (some, any, no, every) }\end{array}$ & I saw _ students \\
\hline DCAR & $\begin{array}{l}\text { Cardinal } \\
\text { (many, few, one, two) }\end{array}$ & $\begin{array}{l}\text { There are_people in } \\
\text { this room } \\
\text { She read a_books }\end{array}$ \\
\hline D-plural & Plural morpheme $-s$, -en & $\begin{array}{l}\text { The child_saw } \\
\text { plane_ }\end{array}$ \\
\hline
\end{tabular}

${ }^{\mathrm{a}}$ Context was used to identify some of these errors (compare with grammatical examples).

Table 7

Sample incorrect use errors for the D-system instantiations coded

\begin{tabular}{lll}
\hline Code & Specific morpheme $(\mathrm{s})^{\mathrm{a}}$ & Example \\
\hline D-'s & Possessive morpheme 's & John's's book is on the table \\
D-plural & Plural instead of singular & I see a rollerskates
\end{tabular}

${ }^{a}$ Context was used to identify some of these errors (compare with grammatical examples).
Table 8 presents the set of elements associated with each of the different instantiations of the C-system that we included in our analyses, and Table 9 provides omis-

Table 8

C-system instantiations coded

\begin{tabular}{lll}
\hline Code & Specific morpheme(s) & Example \\
\hline CCOM & $\begin{array}{l}\text { that }, \text { if } \text { (argument), } \\
\text { whether, for } \\
\text { (complementizers of } \\
\text { argument clauses) }\end{array}$ & $\begin{array}{l}\text { I know that he is leaving } \\
\text { I wonder if/whether he is } \\
\text { leaving }\end{array}$ \\
\end{tabular}

CADJ because, after, if (adjunct), I stayed at school because it when (complementizers of was raining adjunct clauses)

I went to school after I had breakfast

I will stay at school if it rains

CWH who, what, where, why, how Who has finished his soup? (in main and embedded clauses) I wonder who has finished his soup

Why are you laughing? I wonder why he is laughing

CREL who (subject and object), I saw the man who was leaving that, where, which I saw the man who you pushed I visited the place where you were staying

That's the kind of person that she is

I lost my dog which I loved very much

CAUX Fronted forms of

be, have, do;

Fronted modals

Is he going to the store?

(can, must, may, will, shall)

Can I have the salt, please? Will she pass the exam?

Table 9

Sample omission errors for the C-system instantiations coded

\begin{tabular}{lll}
\hline Code & Specific morpheme $(\mathrm{s})^{\mathrm{a}}$ & Example \\
\hline CCOM & that, if, whether, for & I wonder_he is leaving
\end{tabular}
(complementizers of argument clauses)

CADJ because, after, if (adjunct), I stayed at school_it when (complementizers of was raining adjunct clauses)

I went to school_ I had breakfast.

I will stay at school_ it rains

CWH who, what, where, why, how _ has finished his soup? (in main and embedded I wonder_has finished clauses)

his soup _ are you laughing?

I wonder_he is laughing

CREL who (subject and object), I saw the man _ was that, where, which

leaving

I lost my dog _ I loved

CAUX Fronted forms of _ he going to the store?

be, have, do

Fronted modals _ I have the salt, please? (can, must, may, will, shall) _ $\quad$ she pass the exam?

${ }^{a}$ Context and intonation were used to identify some of these errors (compare with grammatical examples). 
sion example errors related to the structures presented in Table 8. Because C-system elements are all free-standing morphemes, incorrect $\mathrm{C}$-system use errors are lexical errors, except for errors involving CREL, as illustrated in (6): Thus, we have not included a table illustrating such errors.

(6) This is the thing he goes boom! ('This is the thing that goes boom!')

\section{Results}

Error rates were calculated by dividing the number of errors by the number of obligatory contexts for use of that structure. We now present the results comparing left with right side resections as groups (LHG vs. RHG) as well as comparing the left and right hemisphere groups with similar etiologies. Table 10 presents I-system (AGRS/T) and aspect (AGRO) error rates by side of removal. Table 11 shows the AGRS/T and AGRO error rates by side of removal as well as etiology. All errors reflect non-adult-like omissions, unless otherwise indicated.

As Table 10 shows, the LH group as a whole had a higher I-system error rate than the RH group, and both

Table 10

Mean error rates for I-system (AGRS/T + AGRO) by side of removal

\begin{tabular}{lll}
\hline & AGRS/T $(\%)$ & AGRO $(\%)$ \\
\hline LH & 10.2 & 5.8 \\
RH & 3.2 & 0 \\
\hline
\end{tabular}

Table 11

Mean error rates for I-system (AGRS/T + AGRO) by side of removal and etiology

\begin{tabular}{llllll}
\hline & AGRS/T & & & AGRO \\
\cline { 2 - 3 } \cline { 6 - 7 } & Infarct & RE & & Infarct (\%) & RE (\%) \\
\hline LH & 11.9 & 9.2 & & 0 & 8.1 \\
RH & 6.9 & 2.6 & & 0 & 0 \\
\hline
\end{tabular}

the LH infarct and LH RE subgroups had notably higher I-system error rates than their $\mathrm{RH}$ counterparts as can be seen in Table 11. Tables 12-15 below summarize the data for the individual children by etiology/side-ofremoval group for AGRS/T and AGRO.

As Tables 12-15 show, the majority of I-system errors consist of illegitimate omissions. The tables also reflect the fact that MP, one of the two members of the RH infarct group, had very few instantiations of I, making it somewhat difficult to draw conclusions regarding the effects on the production of I-system elements after infarct. Moreover, because MP had so few instantiations of I (only 7 in total), the errors she made substantially raised the error rate for the RH infarct group. Therefore, the rate of error for this group may not be well represented. However, as we shall see below in the pair-wise comparisons (Tables 16-20), all of the other pairs reflect the pattern of a greater I-system error rate for the child following left hemispherectomy, regardless of the etiology group, consistent with our first prediction. Moreover, as all of the children, regardless of side of resection produced overt instantiations of $\mathrm{I}$, our second and third predictions are also supported.

The error rate of this pair is clearly consistent with our prediction. GG, the left hemispherectomy, produces $41 / 2$ times more errors with respect to AGRS/T than his right hemispherectomy counterpart, JE, despite their similar incidence of use (62 vs. 52). Essentially across the board, GG shows more I-system errors than does JE.

Table 13

$\%$ Error for the $A G R O$ (aspect) instantiations per child with infarct

\begin{tabular}{|c|c|c|c|c|c|}
\hline & Child & $\begin{array}{l}\text { Regular } \\
\text { past participle }\end{array}$ & $\begin{array}{l}\text { Irregular past } \\
\text { participle }\end{array}$ & Progressive & Total \\
\hline LH & $\begin{array}{l}1 \mathrm{GG} \\
2 \mathrm{SM}\end{array}$ & $\begin{array}{l}-0 / 0 \\
0 \% 0 / 1\end{array}$ & $\begin{array}{l}0 \% 0 / 2 \\
0 \% 0 / 6\end{array}$ & $\begin{array}{l}-0 / 0 \\
0 \% 0 / 6\end{array}$ & $\begin{array}{l}0 \% 0 / 2 \\
0 \% 0 / 13\end{array}$ \\
\hline \multicolumn{2}{|c|}{ Mean error \% } & & & & $0 \%(0 / 15)$ \\
\hline RH & $\begin{array}{l}1 \mathrm{JE} \\
2 \mathrm{MP}\end{array}$ & $\begin{array}{l}0 \% 0 / 1 \\
-0 / 0\end{array}$ & $\begin{array}{l}-0 / 0 \\
0 \% 0 / 1\end{array}$ & $\begin{array}{l}0 \% 0 / 4 \\
-0 / 0\end{array}$ & $\begin{array}{l}0 \% 0 / 5 \\
0 \% 0 / 1\end{array}$ \\
\hline \multicolumn{2}{|c|}{ Mean error \% } & & & & $0 \%(0 / 6)$ \\
\hline
\end{tabular}

Table 12

$\%$ Error for the $A G R S / T$ instantiations per child with infarct

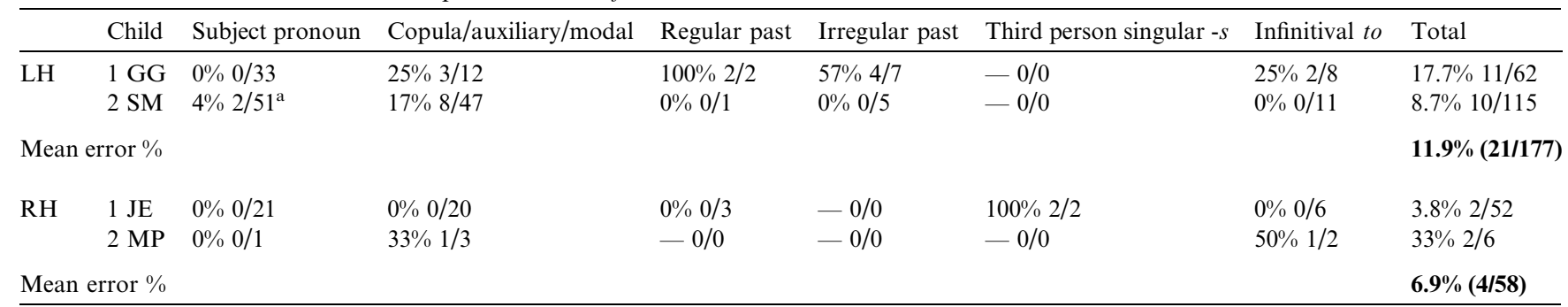

${ }^{\text {a }}$ One incorrect use error. 
Table 14

$\%$ Error for the $A G R S / T$ instantiations per child with $R E$

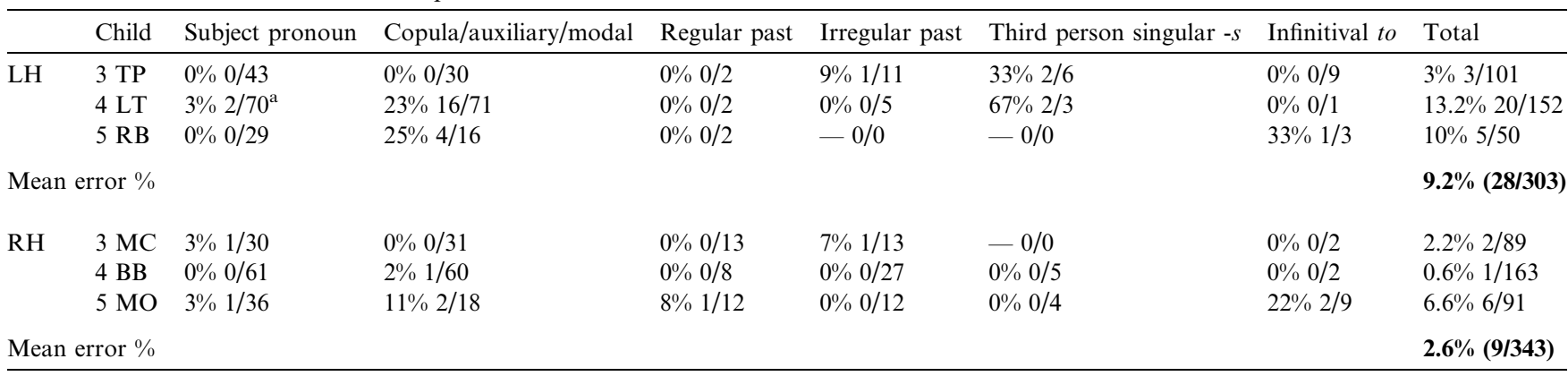

${ }^{\mathrm{a}}$ One incorrect use error.

Table 15

$\%$ Error for the $A G R O$ (aspect) instantiations per child with $R E$

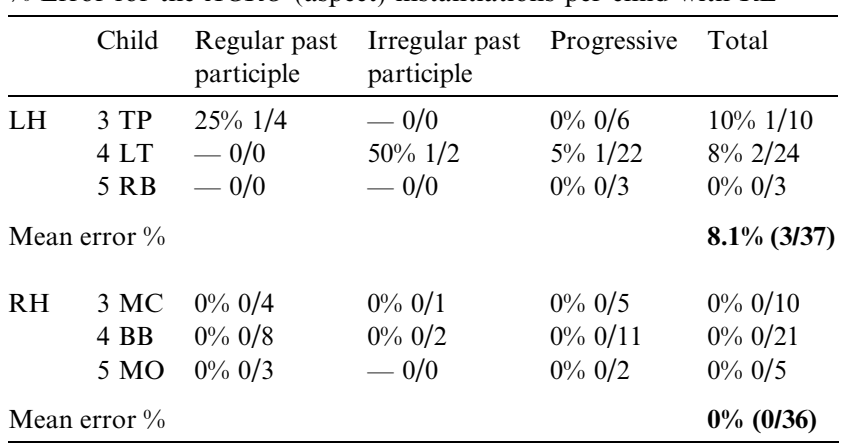

Neither GG, nor JE has any AGRO/Aspect errors, or many instantiations of Aspect, for that matter.

Here, the child with right hemispherectomy, MP, shows a greater error rate than her left hemispherectomy pair, SM. However, as was mentioned above, MP has the lowest use of I-system elements of all the children studied, exaggerating the effect of each error she made.

Neither TP nor MC make many AGRS/T errors, both rates falling in the range of what could be considered performance errors. In terms of AGRO/Aspect, $\mathrm{TP}$, who underwent left hemispherectomy, performs more poorly than MC ( $10 \%$ vs. $0 \%$ errors), as expected.

Table 16

GG vs. JE

\begin{tabular}{|c|c|c|c|c|c|c|c|c|c|c|c|}
\hline Child & $\begin{array}{l}\text { Subject } \\
\text { pronoun }\end{array}$ & Cop/aux/modal & $\begin{array}{l}\text { Regular } \\
\text { past }\end{array}$ & $\begin{array}{l}\text { Irregular } \\
\text { past }\end{array}$ & 3rd p. sg. $-s$ & Inf. to & Total AGRS/T & $\begin{array}{l}\text { Reg. past } \\
\text { part. }\end{array}$ & $\begin{array}{l}\text { Irreg. past } \\
\text { part. }\end{array}$ & Progr. & $\begin{array}{l}\text { Total } \\
\text { AGRO }\end{array}$ \\
\hline & $60 / 33$ & & $100^{\circ}$ & $57 \% 4 / 7$ & & & & 0 & $0 \% 0 / 2$ & & $0 \% 0 / 2$ \\
\hline JE & $0 \% 0 / 21$ & $0 \% 0 / 20$ & $0 \% 0 / 3$ & $-0 / 0$ & $100 \% 2 / 2$ & $0 \% 0 / 6$ & $3.8 \% 2 / 52$ & $0 \% 0 / 1$ & $-0 / 0$ & $0 \% 0 / 4$ & $0 \% 0 / 5$ \\
\hline
\end{tabular}

Table 17

SM vs. MP

\begin{tabular}{|c|c|c|c|c|c|c|c|c|c|c|c|}
\hline Child & $\begin{array}{l}\text { Subject } \\
\text { pronoun }\end{array}$ & Cop/aux/mod & $\begin{array}{l}\text { Regular } \\
\text { past }\end{array}$ & $\begin{array}{l}\text { Irreg. } \\
\text { past }\end{array}$ & 3rd p.sg. $-s$ & Inf. to & Total AGRS/T & $\begin{array}{l}\text { Reg. past } \\
\text { part. }\end{array}$ & $\begin{array}{l}\text { Irreg. past } \\
\text { part. }\end{array}$ & Progr. & $\begin{array}{l}\text { Total } \\
\text { AGRO }\end{array}$ \\
\hline SM & $4 \% 2 / 51^{a}$ & $17 \% 8 / 47$ & $0 \% 0 / 1$ & $0 \% 0 / 5$ & $-0 / 0$ & $0 \% 0 / 11$ & $8.7 \% 10 / 115$ & $0 \% 0 / 1$ & $0 \% 0 / 6$ & $0 \% 0 / 6$ & $0 \% 0 / 13$ \\
\hline MP & $0 \% 0 / 1$ & $33 \% 1 / 3$ & $-0 / 0$ & $-0 / 0$ & $-0 / 0$ & $50 \% 1 / 2$ & $33 \% 2 / 6$ & $-0 / 0$ & $0 \% 0 / 1$ & $-0 / 0$ & $0 \% 0 / 1$ \\
\hline
\end{tabular}

${ }^{\text {a }}$ One incorrect use error.

Table 18

TP vs. MC

\begin{tabular}{|c|c|c|c|c|c|c|c|c|c|c|c|}
\hline Child & $\begin{array}{l}\text { Subject } \\
\text { pronoun }\end{array}$ & Cop/aux/mod & $\begin{array}{l}\text { Regular } \\
\text { past }\end{array}$ & Irreg. past & 3rd p.sg. $-s$ & Inf. to & Total AGRS/T & $\begin{array}{l}\text { Reg. past } \\
\text { part. }\end{array}$ & $\begin{array}{l}\text { Irreg. past } \\
\text { part. }\end{array}$ & Progr. & $\begin{array}{l}\text { Total } \\
\text { AGRO }\end{array}$ \\
\hline ТP & $0 \% 0 / 43$ & $0 \% 0 / 30$ & $0 \% 0 / 2$ & $9 \% 1 / 11$ & $33 \% 2 / 6$ & $0 \% 0 / 9$ & $3 \% 3 / 101$ & $25 \% 1 / 4$ & $-0 / 0$ & $0 \% 0 / 6$ & $10 \% 1 / 10$ \\
\hline $\mathrm{MC}$ & $3 \% 1 / 30$ & $0 \% 0 / 31$ & $0 \% 0 / 13$ & $7 \% 1 / 13$ & $-0 / 0$ & $0 \% 0 / 2$ & $2.2 \% 2 / 89$ & $0 \% 0 / 4$ & $0 \% 0 / 1$ & $0 \% 0 / 5$ & $0 \% 0 / 10$ \\
\hline
\end{tabular}

Table 19

LT vs. BB

\begin{tabular}{|c|c|c|c|c|c|c|c|c|c|c|c|}
\hline Child & $\begin{array}{l}\text { Subject } \\
\text { pronoun }\end{array}$ & Cop/aux/mod & $\begin{array}{l}\text { Regular } \\
\text { past }\end{array}$ & Irreg. past & 3rd p.sg. $-s$ & Inf. to & Total AGRS/T & $\begin{array}{l}\text { Reg. past } \\
\text { part. }\end{array}$ & $\begin{array}{l}\text { Irreg. past } \\
\text { part. }\end{array}$ & Progr. & $\begin{array}{l}\text { Total } \\
\text { AGRO }\end{array}$ \\
\hline LT & $3 \% 2 / 70^{\mathrm{a}}$ & $23 \% 16 / 71$ & $0 \% 0 / 2$ & $0 \% 0 / 5$ & $67 \% 2 / 3$ & $0 \% 0 / 1$ & $13.2 \% 20 / 152$ & $-0 / 0$ & $50 \% 1 / 2$ & $5 \% 1 / 22$ & $8 \% 2 / 24$ \\
\hline BB & $0 \% 0 / 61$ & $2 \% 1 / 60$ & $0 \% 0 / 8$ & $0 \% 0 / 27$ & $0 \% 0 / 5$ & $0 \% 0 / 2$ & $0.6 \% 1 / 163$ & $0 \% 0 / 8$ & $0 \% 0 / 2$ & $0 \% 0 / 11$ & $0 \% 0 / 21$ \\
\hline
\end{tabular}

\footnotetext{
${ }^{\mathrm{a}}$ One incorrect use error.
} 
Table 20

RB vs. MO

\begin{tabular}{|c|c|c|c|c|c|c|c|c|c|c|c|}
\hline Child & $\begin{array}{l}\text { Subject } \\
\text { pronoun }\end{array}$ & Cop/aux/mod & $\begin{array}{l}\text { Regular } \\
\text { past }\end{array}$ & Irreg. past & 3rd p.sg. $-s$ & Inf. to & Total AGRS/T & $\begin{array}{l}\text { Reg. past } \\
\text { part. }\end{array}$ & $\begin{array}{l}\text { Irreg. past } \\
\text { part. }\end{array}$ & Progr. & $\begin{array}{l}\text { Total } \\
\text { Aspect }\end{array}$ \\
\hline & \% $0 / 29$ & & $2<0<$ & $-0 / 0$ & $-0 / 0$ & & & $-0 / 0$ & $-0 / 0$ & & \\
\hline MO & $3 \% 1 / 36$ & $11 \% 2 / 18$ & $8 \% 1 / 12$ & $0 \% 0 / 12$ & $0 \% 0 / 4$ & $22 \% 2 / 9$ & $6.6 \% 6 / 91$ & $0 \% 0 / 3$ & $-0 / 0$ & $0 \% 0 / 2$ & $0 \% 0 / 5$ \\
\hline
\end{tabular}

Here we find a clear difference in the predicted direction. LT, the child with left hemispherectomy, has a notably higher error rate for each AGRS/T-element appearing in her sample, resulting in a total of $13.2 \%$ errors, vs. $0.6 \%$ errors by $\mathrm{BB}$, her right hemispherectomy counterpart. Similarly, LT makes more errors with respect to AGRO/Aspect ( $8 \%$ ) than $\mathrm{BB}(0 \%)$.

The performance of these two children is also in the predicted direction, although the difference is not great: RB, with left hemispherectomy, produces $10 \%$ AGRS/T

Table 21

Mean error rates for D-system by side of removal

\begin{tabular}{ll}
\hline LH & $7.3 \%$ \\
RH & $3.1 \%$ \\
\hline
\end{tabular}

Table 22

Mean error rates for D-system by side of removal and etiology

\begin{tabular}{lll}
\hline & Infarct $(\%)$ & RE $(\%)$ \\
\hline LH & 7.1 & 7.3 \\
RH & 3.4 & 3.0 \\
\hline
\end{tabular}

errors versus MO's (RH) error rate of $6.6 \%$. Neither of the two children produced any AGRO/Aspect errors.

The D-system error rates for the LHG and RHG are presented in Tables 21 and 22.

As Tables 21 and 22 show, we find the same pattern of results with the D-system. Comparing the subjects by side of removal, both LH etiology subgroups combined make more errors than their RHG counterparts ( $7.3 \%$ vs. $3.1 \%$, respectively). Examining etiology, the LH infarct subgroup vs. the RH infarct subgroup error rates are $7.1 \%$ vs. 3.4\%, respectively; and the LH RE subgroup error rate is $7.3 \%$ vs. $3.0 \%$ for the $\mathrm{RH} \mathrm{RE}$ subgroup.

Thus, although error rates are low, the LHG displays an error rate more than twice that of the RHG. In addition, in the subgroups defined by etiology, both the LH infarct subgroup and the LH RE subgroup make slightly more than twice the rate of errors of the RH etiology subgroups. These findings are consistent with all of our predictions.

In Tables 23 and 24 we present the individual results by etiology/side of removal.

Table 23

$\%$ Error for the D instantiations per child with infarct

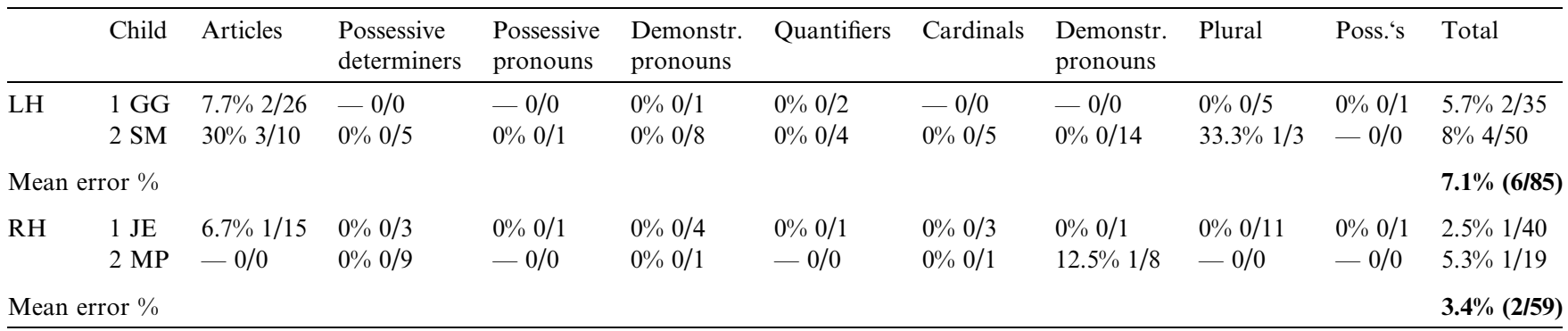

Table 24

$\%$ Error for the D instantiations per child with $R E$

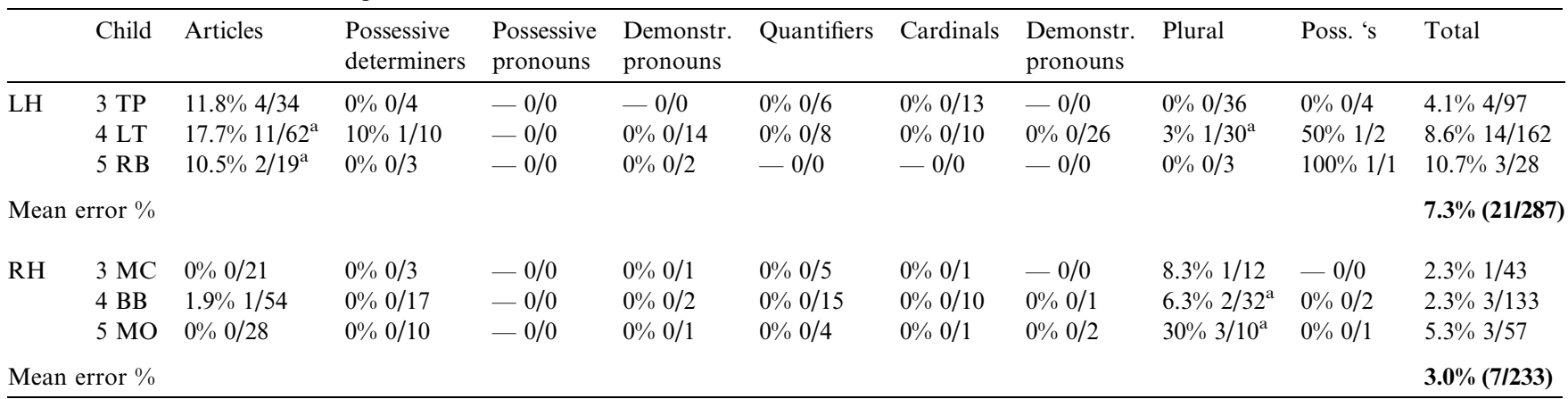

\footnotetext{
${ }^{a}$ One incorrect use error.
} 
Looking at article omissions in particular, the Dstructure with the greatest number of obligatory contexts for usage in our transcripts, we find quite clear differences in error rate by side: $14.6 \%$ for the LHG vs. $1.7 \%$ for the RHG overall. Comparing by etiology subgroups, we find large discrepancies in the production of articles: a $13.9 \%$ rate of error for the LH infarct group vs. a $6.7 \%$ rate of error of for the $\mathrm{RH}$ infarct group (which had only 1 subject who used articles) and a $14.8 \%$ rate of error vs. $0.97 \%$ for the LH vs. RH RE subgroups, respectively, a more than 15 -fold difference. Given the high number of obligatory contexts for articles in both groups (LH: 151 and RH: 118), this difference in error rate is perhaps the most revealing difference with respect to production of D-system elements, and this result supports prediction 1 .
The second most frequent D-system errors were with plurals, with omissions and incorrect use more equal in occurrence: 1 omission, 2 incorrect uses in the LHG; 4 omissions, 2 incorrect uses in the RHG. However, here, the rate of error goes against our first prediction. The LHG's error rate is $2.6 \%$, while the RHG's error rate is $9.2 \%$. Nevertheless, 3 of the 5 LHG children had 5 or fewer plural contexts in their data, while only 1 of the RHG children had fewer than 10 plural contexts in her data. It is difficult, therefore, to know what to make of this specific result in light of the variability in these data. Moreover, they do not affect the overall findings that by side and by etiology, the children who underwent left hemispherectomy have a higher rate of error than those who underwent right hemispherectomy, as will become evident in the pair comparisons that follow below in Tables 25-29.

Table 25

GG vs. JE

\begin{tabular}{|c|c|c|c|c|c|c|c|c|c|c|}
\hline Child & Articles & $\begin{array}{l}\text { Possessive } \\
\text { determiners }\end{array}$ & $\begin{array}{l}\text { Possessive } \\
\text { pronouns }\end{array}$ & $\begin{array}{l}\text { Demonstr. } \\
\text { pronouns }\end{array}$ & Quantifiers & Cardinals & $\begin{array}{l}\text { Demonstr. } \\
\text { pronouns }\end{array}$ & Plural & Poss. 's & Total \\
\hline GG & $8 \% 2 / 26$ & $-0 / 0$ & $-0 / 0$ & $0 \% 0 / 1$ & $0 \% 0 / 2$ & $-0 / 0$ & $-0 / 0$ & $0 \% 0 / 5$ & $0 \% 0 / 1$ & $5.7 \% 2 / 35$ \\
\hline JE & $7 \% 1 / 15$ & $0 \% 0 / 3$ & $0 \% 0 / 1$ & $0 \% 0 / 4$ & $0 \% 0 / 1$ & $0 \% 0 / 2$ & $0 \% 0 / 1$ & $0 \% 0 / 11$ & $0 \% 0 / 1$ & $2.5 \% 1 / 40$ \\
\hline
\end{tabular}

Table 26

SM vs. MP

\begin{tabular}{|c|c|c|c|c|c|c|c|c|c|c|}
\hline Child & Articles & $\begin{array}{l}\text { Possessive } \\
\text { determiners }\end{array}$ & $\begin{array}{l}\text { Possessive } \\
\text { pronouns }\end{array}$ & $\begin{array}{l}\text { Demonstr. } \\
\text { pronouns }\end{array}$ & Quantifiers & Cardinals & $\begin{array}{l}\text { Demonstr. } \\
\text { pronouns }\end{array}$ & Plural & Poss. 's & Total \\
\hline SM & $30 \% 3 / 10$ & $0 \% 0 / 5$ & $0 \% 0 / 1$ & $0 \% 0 / 8$ & $0 \% 0 / 4$ & $0 \% 0 / 5$ & $0 \% 0 / 14$ & $33 \% 1 / 3$ & $-0 / 0$ & $8 \% 4 / 50$ \\
\hline MP & $-0 / 0$ & $0 \% 0 / 9$ & $-0 / 0$ & $0 \% 0 / 1$ & $0 \% 0 / 1$ & $0 \% 0 / 3$ & $13 \% 1 / 8$ & $-0 / 0$ & $-0 / 0$ & $5.3 \% 1 / 19$ \\
\hline
\end{tabular}

Table 27

TP vs. MC

\begin{tabular}{|c|c|c|c|c|c|c|c|c|c|c|}
\hline Child & Articles & $\begin{array}{l}\text { Possessive } \\
\text { determiners }\end{array}$ & $\begin{array}{l}\text { Possessive } \\
\text { pronouns }\end{array}$ & $\begin{array}{l}\text { Demonstr. } \\
\text { pronouns }\end{array}$ & Quantifiers & Cardinals & $\begin{array}{l}\text { Demonstr. } \\
\text { pronouns }\end{array}$ & Plural & Poss. 's & Total \\
\hline $\mathrm{TP}$ & $12 \% 4 / 34$ & $0 \% 0 / 4$ & $-0 / 0$ & $-0 / 0$ & $0 \% 0 / 6$ & $0 \% 0 / 13$ & $-0 / 0$ & $0 \% 0 / 36$ & $0 \% 0 / 4$ & $4.1 \% 4 / 97$ \\
\hline $\mathrm{MC}$ & $0 \% 0 / 21$ & $0 \% 0 / 3$ & $-0 / 0$ & $0 \% 0 / 1$ & $0 \% 0 / 5$ & $0 \% 0 / 1$ & $-0 / 0$ & $8 \% 1 / 12$ & $-0 / 0$ & $2.3 \% 1 / 43$ \\
\hline
\end{tabular}

Table 28

LT vs. BB

\begin{tabular}{lllllllllll}
\hline Child & Articles & $\begin{array}{l}\text { Possessive } \\
\text { determiners }\end{array}$ & $\begin{array}{l}\text { Possessive } \\
\text { pronouns }\end{array}$ & $\begin{array}{l}\text { Demonstr. } \\
\text { pronouns }\end{array}$ & Quantifiers & Cardinals & $\begin{array}{l}\text { Demonstr. } \\
\text { pronouns }\end{array}$ & Plural & Poss. 's & Total \\
\hline LT & $18 \% 11 / 62^{\mathrm{a}}$ & $10 \% 1 / 10$ & $-0 / 0$ & $0 \% 0 / 14$ & $0 \% 0 / 8$ & $0 \% 0 / 10$ & $0 \% 0 / 26$ & $3 \% 1 / 30^{\mathrm{a}}$ & $50 \% 1 / 2$ & $\mathbf{8 . 6} \% \mathbf{1 4} / \mathbf{1 6 2}$ \\
BB & $2 \% 1 / 54$ & $0 \% 0 / 17$ & $-0 / 0$ & $0 \% 0 / 2$ & $0 \% 0 / 15$ & $0 \% 0 / 10$ & $0 \% 0 / 2$ & $6 \% 2 / 32$ & $0 \% 0 / 1$ & $\mathbf{2 . 3} \% \mathbf{3 / 1 3 3}$ \\
\hline
\end{tabular}

a One incorrect use error.

Table 29

RB vs. MO

\begin{tabular}{|c|c|c|c|c|c|c|c|c|c|c|}
\hline Child & Articles & $\begin{array}{l}\text { Possessive } \\
\text { determiners }\end{array}$ & $\begin{array}{l}\text { Possessive } \\
\text { pronouns }\end{array}$ & $\begin{array}{l}\text { Demonstr. } \\
\text { pronouns }\end{array}$ & Quantifiers & Cardinals & $\begin{array}{l}\text { Demonstr. } \\
\text { pronouns }\end{array}$ & Plural & Poss. ‘s & Total \\
\hline RB & $11 \% 2 / 19^{a}$ & $0 \% 0 / 3$ & $-0 / 0$ & $0 \% 0 / 2$ & $-0 / 0$ & $-0 / 0$ & $-0 / 0$ & $0 \% 0 / 3$ & $100 \% 1 / 1$ & $10.7 \% 3 / 28$ \\
\hline MO & $0 \% 0 / 28$ & $0 \% 0 / 10$ & $-0 / 0$ & $0 \% 0 / 1$ & $0 \% 0 / 4$ & $0 \% 0 / 1$ & $0 \% 0 / 2$ & $30 \% 3 / 10^{\mathrm{a}}$ & $0 \% 0 / 1$ & $5.3 \% 3 / 57$ \\
\hline
\end{tabular}

${ }^{a}$ One incorrect use error. 
JE, the child with right hemispherectomy, uses every D-system structure, while we find evidence of only $5 \mathrm{D}$ elements in his left hemispherectomy counterpart, GG. ${ }^{10}$ In addition, GG's error rate is twice that of JE. The comparative error rates from this pair, then, are consistent with our first prediction.

Note first that MP produces more instantiations of D-system elements than she does I-system elements. Nevertheless, MP's numbers of both types and tokens of D-elements are far lower than those of her left hemispherectomy counterpart, SM. The difference in error rate between SM and MP is small, although in the predicted direction; namely, SM, the child with left hemispherectomy has a higher error rate than her right hemispherectomy counterpart.

Similar to their performance with regard to the Isystem, both TP and MC used a majority of the Dsystem elements we examined, and neither made many errors. MC's error rate falls not only within the range of error rate reported for children in early stages of grammatical development (Platzack, 2001; Poulisse, 1999, (Chapter 2); Stemberger, 1989), but an error rate of less than $5 \%$ may well fall within the adult error rate as well (e.g., Bock, 1991). ${ }^{11}$ What is important to note is the very low error rate of both children, with the error rate of MC falling within a rate typically considered "noise" in the data. Nevertheless, as predicted, TP, the child with left hemispherectomy, made more errors than his right hemispherectomy pair, MC.

Both LT and BB evidenced almost the full range of D-elements in their grammars. As predicted however, the child with left hemispherectomy, LT, had a higher error rate overall than her right hemispherectomy counterpart, whose error rate also falls within the rate reported for normal adults.

With this pair as well, we find a greater error rate for the child with left hemispherectomy, in this case, RB. We also find that the child with right hemispherectomy, MO has a richer instantiation of DP in his grammar compared to RB. ${ }^{12}$

Turning now to the $\mathrm{C}$-system, the overall results are presented in Tables 30 and 31:

As can be seen in Table 31, the LHG made slightly more C-errors, both in the infarct $(1.5 \%$ vs. $0 \%$ in the RHG) and in the RE group (3.4\% vs. $3.1 \%$ in the RHG), again supporting our first prediction. Further-

\footnotetext{
${ }^{10} \mathrm{GG}$, TP, and LT have gone on to develop fluent, mature grammars, as have MC and MO. The data presented here reflect their performance at an earlier stage of their linguistic development.

${ }^{11}$ Stemberger and Bock's studies (and others reviewed in Poulisse, 1999) report on rates of various types of "slips of the tongue", i.e., performance errors, not grammatical "errors" of the sort we are concerned with here.

${ }^{12}$ This has continued to be the case in our longitudinal investigation of their language development.
}

Table 30

Mean error rates for C-system by side of removal

\begin{tabular}{ll}
\hline LH & $2.1 \%$ \\
RH & $2.7 \%$ \\
\hline
\end{tabular}

Table 31

Mean error rates for C-system by side of removal and etiology

\begin{tabular}{lll}
\hline & Infarct $(\%)$ & RE $(\%)$ \\
\hline LH & 1.5 & 3.4 \\
RH & 0 & 3.1 \\
\hline
\end{tabular}

more, similar to our results for the I- and the D-system, the LHG and RHG had almost equivalent low error rates with respect to the $\mathrm{C}$-system, supporting our second and third prediction.

Tables 32 and 33 show the individual results by etiology/side of removal:

Comparing the two side-of-removal groups, we see in Tables 32 and 33 that the numbers of total C-instantiations are very similar (LHG: 97; RHG: 111). No child in the LHG failed to have overt C-structures, while one of the RHG children did: MP. MP produced only short, one-clause utterances and no questions; therefore, no contexts in which we would be able to see overt C structures. Notice also that the children in the LHG produce relatively few C-structures, with one exception: SM. The children with right hemispherectomy each show a more substantial number of C-structures, ranging from 15 to 40, except for MP, SM's counterpart.

If we calculate the numbers without the second pair (SM/MP), who are so "mis-matched" regarding the Csystem, the following picture arises:

- LHG: 2.9\% (1/34) errors and 34 instantiations; RHG: $2.7 \%(3 / 111)$ errors and 111 instantiations

- LH infarct group: $0 \%(0 / 5)$ errors and 5 instantiations; RH infarct group: $0 \%(0 / 15)$ and 15 instantiations

- LH RE group: 3.4\% (1/29) and 29 instantiations; RH RE group: 3.1\% (3/96) and 96 instantiations.

The remaining infarct pair (GG/JE) shows the difference related to side of surgery in the numbers of C-instantiations, while the RE subgroup shows the predicted difference both in \% of errors (although both error rates are small) and especially in C-system instantiations, with a markedly higher number of overt C-structures produced by the RH RE group (96 as compared to 29 by the LH-RE group). These findings with respect to the $\mathrm{C}$-system are consistent with all three of our predictions.

Tables 34-38 show the comparisons across pairs.

This pair exemplifies well the performance of the $\mathrm{L}$ and $\mathrm{R}$ groups overall - equivalent error rates but with 
Table 32

$\%$ Error for the $\mathrm{C}$ instantiations per child with infarct

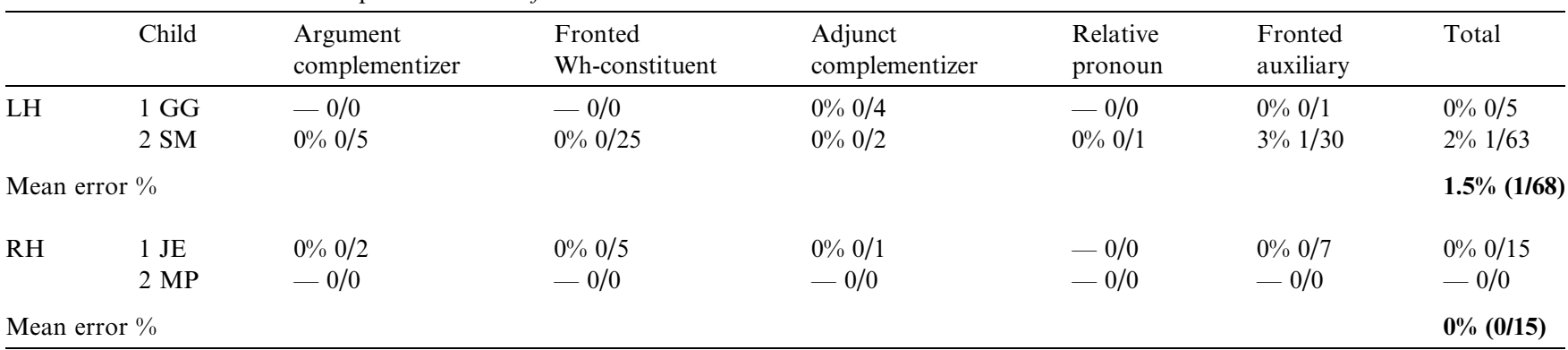

Table 33

$\%$ Error for the $\mathrm{C}$ instantiations per child with $R E$

\begin{tabular}{|c|c|c|c|c|c|c|c|}
\hline & Child & $\begin{array}{l}\text { Argument } \\
\text { complementizer }\end{array}$ & $\begin{array}{l}\text { Fronted } \\
\text { Wh-constituent }\end{array}$ & $\begin{array}{l}\text { Adjunct } \\
\text { complementizer }\end{array}$ & $\begin{array}{l}\text { Relative } \\
\text { pronoun }\end{array}$ & $\begin{array}{l}\text { Fronted } \\
\text { auxiliary }\end{array}$ & Total \\
\hline \multirow[t]{3}{*}{$\mathrm{LH}$} & $3 \mathrm{TP}$ & $0 \% \quad 0 / 1$ & $0 \% 0 / 3$ & $0 \% 0 / 3$ & $-0 / 0$ & $0 \% 0 / 3$ & $0 \% 0 / 10$ \\
\hline & $4 \mathrm{LT}$ & $0 \% \quad 0 / 1$ & $0 \% 0 / 3$ & $0 \% \quad 0 / 1$ & $-0 / 0$ & $0 \% 0 / 3$ & $0 \% 0 / 8$ \\
\hline & $5 \mathrm{RB}$ & $-0 / 0$ & $0 \% 0 / 6$ & $-0 / 0$ & $-0 / 0$ & $20 \% 1 / 5$ & $9.1 \% 1 / 11$ \\
\hline \multicolumn{3}{|c|}{ Mean error $\%$} & & & & & $3.4 \%(1 / 29)$ \\
\hline \multirow[t]{3}{*}{$\mathrm{RH}$} & $3 \mathrm{MC}$ & $0 \% 0 / 8$ & $-0 / 0$ & $0 \% 0 / 11$ & $0 \% 0 / 1$ & $-0 / 0$ & $0 \% \quad 0 / 20$ \\
\hline & $4 \mathrm{BB}$ & $0 \% 0 / 10$ & $0 \% \quad 0 / 4$ & $0 \% 0 / 20$ & $25 \% 1 / 4$ & $0 \% 0 / 2$ & $2.5 \% 1 / 40$ \\
\hline & $5 \mathrm{MO}$ & $0 \% \quad 0 / 1$ & $0 \% 0 / 9$ & $0 \% 0 / 14$ & $100 \% 1 / 1^{\mathrm{a}}$ & $9.1 \% 1 / 11$ & $5.5 \% 2 / 36$ \\
\hline \multicolumn{3}{|c|}{ Mean error $\%$} & & & & & $3.1 \%(3 / 96)$ \\
\hline
\end{tabular}

a Incorrect use error.

Table 34

GG vs. JE

\begin{tabular}{|c|c|c|c|c|c|c|}
\hline Child & Argument complementizer & Fronted Wh- constituent & Adjunct complementizer & Relative pronoun & Fronted auxiliary & Total \\
\hline GG & $-0 / 0$ & $-0 / 0$ & $0 \% 0 / 4$ & $-0 / 0$ & $0 \% 0 / 1$ & $0 \% 0 / 5$ \\
\hline $\mathrm{JE}$ & $0 \% 0 / 2$ & $0 \% 0 / 5$ & $0 \% 0 / 1$ & $-0 / 0$ & $0 \% 0 / 7$ & $0 \% 0 / 15$ \\
\hline
\end{tabular}

Table 35

SM vs. MP

\begin{tabular}{|c|c|c|c|c|c|c|}
\hline Child & Argument complementizer & Fronted Wh- constituent & Adjunct complementizer & Relative pronoun & Fronted auxiliary & Total \\
\hline SM & $0 \% 0 / 5$ & $0 \% 0 / 25$ & $0 \% 0 / 2$ & $0 \% 0 / 1$ & $3 \% 1 / 30$ & $1.6 \% 1 / 63$ \\
\hline MP & $-0 / 0$ & $-0 / 0$ & $-0 / 0$ & $-0 / 0$ & $-0 / 0$ & $-0 / 0$ \\
\hline
\end{tabular}

Table 36

TP vs. MC

\begin{tabular}{|c|c|c|c|c|c|c|}
\hline Child & Argument complementizer & Fronted Wh- constituent & Adjunct complementizer & Relative pronoun & Fronted auxiliary & Total \\
\hline TP & $0 \% 0 / 1$ & $0 \% 0 / 3$ & $0 \% 0 / 3$ & $-0 / 0$ & $0 \% 0 / 3$ & $0 \% 0 / 10$ \\
\hline $\mathrm{MC}$ & $0 \% 0 / 8$ & $-0 / 0$ & $0 \% 0 / 11$ & $0 \% 0 / 1$ & $-0 / 0$ & $0 \% 0 / 20$ \\
\hline
\end{tabular}

Table 37

LT vs. BB

\begin{tabular}{|c|c|c|c|c|c|c|}
\hline Child & Argument complementizer & Fronted Wh- constituent & Adjunct complementizer & Relative pronoun & Fronted auxiliary & Total \\
\hline LT & $0 \% 0 / 1$ & $0 \% 0 / 3$ & $0 \% 0 / 1$ & $-0 / 0$ & $0 \% 0 / 3$ & $0 \% 0 / 8$ \\
\hline BB & $0 \% 0 / 10$ & $0 \% 0 / 4$ & $0 \% 0 / 20$ & $25 \% 1 / 4$ & $0 \% 0 / 2$ & $2.5 \% 1 / 40$ \\
\hline
\end{tabular}


Table 38

$\mathrm{RB}$ vs. MO

\begin{tabular}{lllllll}
\hline Child & Argument complementizer & Fronted Wh- constituent & Adjunct complementizer & Relative pronoun & Fronted auxiliary & Total \\
\hline RB & $-0 / 0$ & $0 \% 0 / 6$ & $-0 / 0$ & $-0 / 0$ & $20 \% 1 / 5$ & $\mathbf{9 . 1} \% \mathbf{1 / 1 1}$ \\
MO & $0 \% 0 / 1$ & $0 \%(0 / 9)$ & $0 \% 0 / 14$ & $100 \% 1 / 1^{\mathrm{a}}$ & $9.1 \% 1 / 11$ & $\mathbf{5 . 5} \% \mathbf{2 / 3 6}$ \\
\hline
\end{tabular}

${ }^{\mathrm{a}}$ One incorrect use error.

few instantiations of $\mathrm{C}$ in the speech of the child with left hemispherectomy.

There are no instances of C in MP's sample, in contrast to SM, the child with left hemispherectomy, who has at least one example of every C-instantiation, the only LHG child to do so. This result is rather unexpected. However it should be kept in mind, as mentioned above, that MP had the least developed language of the 10 children in the study; and therefore, given the early stage of grammatical development our sample of her language reflects (only single clause utterances, with no questions and thus no subject-aux inversion), it is not unexpected that there would be no instantiations of $\mathrm{C}$ in MP's speech.

Here there is a trade-off of sorts. The child with left hemispherectomy, TP, produced more different types of C-structures, but had only half as many tokens as MC overall.

LT has a slightly lower error rate than her RHG-pair BB. However, BB has both a much greater number of Csystem tokens as well as a greater range of $\mathrm{CP}$ structures.

This pair performs as predicted. The child with left hemispherectomy, $\mathrm{RB}$, has fewer instances of $\mathrm{C}$; a narrower range of $\mathrm{C}$-structure types, and a higher error rate.

\section{Summary of results}

First, the error percentages obtained for both the LHG and the RHG are surprisingly low across functional systems. Overall, we see that the children with left hemispherectomy produce slightly more errors than the children with right hemispherectomy in their production of function morphemes. This difference is clearest in the I- and the D-system, whereas the C-system shows a difference only in actual usage of C-structures: most children with left hemispherectomy use fewer types and tokens of C-elements than their $\mathrm{RH}$ counterparts.

\section{Discussion}

Let us now evaluate our results with respect to the predictions we formulated in Section 4. In our first pre- diction, we stated that, controlling for etiology and age, the children who have undergone left-hemispherectomy will evidence a greater error rate in use of functional category elements compared to their right hemispherectomy counterparts. This prediction is generally supported. Overall error rates for the $\mathrm{LH}$ and $\mathrm{RH}$ groups as well as for the etiology subgroups considered separately indicate greater rates of error for the children who underwent left hemispherectomy in all three functional systems.

Nevertheless, because the infarct subgroup was so small, and because one of the two children in the right hemispherectomy infarct group had markedly less developed language than the other children, it is the RE subgroup that perhaps serves as our best source of comparison. Here, the RH-RE group had a lower rate of error and more extensive use of functional elements in all three functional systems we examined, both group-wise and pair-matching-wise. However, the differences in error rates between the $\mathrm{LH}$ and the $\mathrm{RH}$ subgroups and pairs were often quite small and surprisingly low in many instances - comparable to adult spontaneous performance error rates (e.g., Platzack, 2001). Performance on only certain functional elements, in particular AgrS (and to a lesser extent D), showed a clear effect of side of resection. In these instances where there was a clear effect of side, the effect was as predicted, with those with LH resection showing a greater error rate. The higher vulnerability of AgrS and perhaps $\mathrm{D}$, as opposed to $\mathrm{C}$ in the LH-RE group lends support to the hypothesis that it is the core of grammar, i.e., syntax proper that is affected if the left hemisphere is removed. While AgrS is a purely syntactic notion, it is often argued that the functional category $\mathrm{C}$ serves as a link between grammar and pragmatics/discourse, thus suggesting that it fulfills more than just a syntactic function (cf. Hamann, 1996; Hulk \& Mueller, 2000; Rizzi, 1997, among others). Therefore, linguistic knowledge associated with the functional category $\mathrm{C}$ might not be as lateralized as, for example, knowledge of AgrS.

Our results are further strengthened by the fact that other factors such as etiology and age were controlled for in the present study. As Curtiss and de Bode (1999) and Curtiss et al. (2001) point out, etiology is the strongest and best predictive factor for language outcome, as it is the best predictor of the status of the 
remaining hemisphere. They report that of all the etiological subgroups studied, the children with Rasmussen's Encephalitis had the best linguistic outcome, immediately followed by the children with pre-or postnatal infarction. In contrast, the spoken language ranks of children with Cortical Dysplasia (CD) were quite low, and almost all children with CD throughout the resected hemisphere; i.e., those with hemimegalencephaly, failed to develop language altogether. In addition, they report that side of resection does not predict language outcome.

The etiology findings of Curtiss and de Bode fare well with the characteristics of the subjects selected for the present study: the children who had enough language to conduct a grammatical study on had either $\mathrm{RE}$ or infarction (cf. Table 1). ${ }^{13}$ With respect to side, however, our findings are inconsistent with their claims. Matching children as best we could in the current study for chronological age, age at symptom onset, age at surgery, and age at testing, and controlling for etiology, we found that side did matter. The children who had left hemispherectomies made more errors with functional morphemes than their right hemispherectomy counterparts.

Our second prediction - that children with right hemispherectomy will develop normal grammars, exhibiting normal developmental patterns with respect to the functional category systems, eventually attaining the adult functional category systems in the target language - was also supported. The group-wise error rates, 3\% for both the I- and D-system, $0 \%$ for Aspect, and $2 \%$ for the $\mathrm{C}$-system, fall well within the limits of acceptable error percentages (noise), and are comparable to the rate of performance errors made by adults.

However, our data also indicate that the children with left hemispherectomy did not make a great many errors on grammatical morphemes. The error rates of the LHG ranged from $2 \%$ for the C-system to $11 \%$ for the I-system. These results provide clear and direct evidence for our last prediction, namely that "given increasing evidence that early child grammars, normal and abnormal, embody functional categories, even in the course of protracted and impaired linguistic development, the left-hemispherectomied children will, nonetheless, develop grammars which contain the functional categories present in adult English".

The findings of our study, therefore, indicate that even when etiology is controlled for ("factored in"), the grammars of the children with only a right hemisphere are not much "worse" than or different from

\footnotetext{
13 The etiology of Sturge-Weber syndrome also leads to better language outcomes than $\mathrm{CD}$, but there are very few SW children in our population, and we were unable to find any children who could comprise a reasonably matched pair.
}

those of the children with only a left hemisphere. ${ }^{14}$ This suggests indeed that side of hemispherectomy may not be as strong a predictive factor for the acquisition and development of grammar as has been the received wisdom for so long. ${ }^{15}$

Our findings regarding the children with left hemispherectomy bear directly on questions regarding functional plasticity for language, in particular, with respect to its temporal dimension; i.e., a critical period for first language acquisition (e.g., Lenneberg, 1967; Newport, 1988). All of the children with left hemispherectomy became aphasic after hemispherectomy, confirming that resection indeed affected their "language" hemisphere. Yet even when left hemispherectomy was performed at ages where fluent, nearly mature language would have already developed (age 4 and up), the brain displayed the capacity to reorganize itself in such a way as to ensure successful language development, a temporal malleability inconsistent with a strong version of the critical period hypothesis, wherein if language is already lateralized, language (re)acquisition should be severely limited. ${ }^{16}$ What is clearly called for is a more refined understanding of RE and infarction and the effect it has on neural and consequent cognitive and linguistic development.

A few additional observations are in order. First, notwithstanding the fact that the children whose grammars we examined correctly produce functional categories, their grammars may nonetheless not be entirely normal. For example, TP, who underwent left hemispherectomy, clearly has full clause structure, as his performance on $\mathrm{C}$-system structures exemplifies, and

\footnotetext{
${ }^{14}$ As will be noted later in this section with respect to subject TP, it may be the case that subtle but interesting differences between the grammars developed by the isolated left vs. right hemispheres can be seen, further differentiating the two groups. Our basic claim, here, however, is that with respect to the properties of core grammar, namely, functional structure, the two groups appear to differ little.

${ }^{15}$ It is worth noting that other clinical factors, specifically, seizure control and amount of Anti Epileptic Drugs (AEDs), were unpredictive of language outcome. As for seizure control, when we compare SM (LH), who has seizure control with MP (RH), who does not have seizure control, we find that SM had lower error rates. In contrast, when we compare TP (LH), who has seizure control with MC (RH) who does not, it is MC who performs better. Clearly seizure control is not predictive of language outcome. With regard to AEDs, we see no negative effect on language outcome. Comparing LT (LH), who took no AEDs following surgery with BB (RH), who took AEDs at least until 5 years post-surgery, we find that LT consistently outperforms BB. On the other hand, MO (RH) and RB ( $\mathrm{LH})$, who both took AEDs following surgery, did not perform equivalently. (MO outperformed RB.) Thus, like seizure control, we find AEDs not to be predictive of linguistic outcome.

${ }^{16} \mathrm{TP}$, in particular, illustrates this point. His hemispherectomy was performed at age 12;9, clearly beyond even Lenneberg's proposed critical period. Yet, after becoming aphasic, TP went on to develop a rich, fully mature grammar. What is more, as of this writing, GG, who is now a teenager, has also developed a completely mature, adult grammar.
} 
is a fluent, mature speaker in person, with no notable linguistic deficits at any level of grammar. However, there are intriguing quirks in his comprehension data. While his ability to judge the grammaticality of sentences is adult-like, he appears to systematically misunderstand negative factives such as in 7 , regardless of whether the negative is in the matrix (7a) or embedded (7b) clause. ${ }^{17}$

(7) a. John didn't know that dinner was ready

b. John knew that dinner wasn't ready

This comprehension deficit mirrors that reported by Dennis in her studies of children with Sturge-Weber disease who had undergone left but not right hemispherectomy (Dennis, 1980a).

In addition, TP systematically fails to comprehend object clefts as in (8), interpreting them as subject clefts; that is, as structures without object extraction and subsequent long-distance movement of the object to $\mathrm{C}$.

(8) It is the girl that the boy is pushing

A few other children in our larger hemispherectomy series have also shown this same difficulty with object clefts despite an ability to correctly comprehend and judge sentences involving long distance Wh-movement, an intriguing phenomenon calling for further linguistic analysis, given that clefts and Wh-movement are hypothesized to be derived in the same way (cf. Rizzi, 1997).

Second, it is important to note that most of the children who participated in our study are mentally retarded, with mental ages (MA) considerably below their chronological ages (CA) at the time of testing and continuing to the time of this writing. Despite quite low mental ages, however, most children have developed rich language. This discrepancy between overall MA and linguistic maturity provides evidence for the dissociation between language and non-language cognition. Two children in particular show this dissociation: MP and JE. MP, at 13 years CA, had the poorest developed grammar of all the children in our sample and had a very low MA of only 28 months. In striking contrast, with a comparable MA (29 months), JE at CA 7;10 demonstrated a rich grammar, including a wide range of $\mathrm{I}, \mathrm{D}$, and $\mathrm{C}$ instantiations. Marked differences between mental age and linguistic competence are frequent in our large pediatric hemi-

\footnotetext{
${ }^{17}$ The test question for this specific sentence pair is, "Was dinner ready?" to which TP responded either by saying, "no" or "I don't know".
}

spherectomy sample, showing that mental age does not predict language outcome.

\section{Conclusion}

We studied the status of functional categories in the language of 10 children who underwent hemispherectomy and found support for our three predictions: first that controlling for etiology and age, following left hemispherectomy, children evidence a greater error rate in the use of functional category elements compared to their right hemispherectomy counterparts; second, that children with only a left hemisphere develop normal grammars, exhibiting normal developmental patterns with respect to the functional category systems, eventually attaining the adult functional category systems in the target language; and third, even left-hemispherectomied children develop grammars which contain the functional categories present in adult English. Our findings indicate an advantage, albeit a weak advantage, of the left hemisphere over the right for language acquisition. However, they provide strong empirical support that, given the right circumstances, the immature brain shows remarkable functional plasticity for language development and that language acquisition, whether mediated by an isolated right or left hemisphere is highly constrained to follow a developmental course constrained and guided by the principles that define Universal Grammar.

\section{Acknowledgments}

This research was supported by NIH Grant NS39505. We are particularly grateful to the children who participated in this research as well as their families, all of whom have inspired and humbled us.

\section{References}

Aram, D. (1988). Language sequelae of unilateral brain lesions in children. In F. Plum (Ed.), Language, communication, and the brain. New York: Raven Press.

Aram, D. M. (1999). Neuroplasticity: evidence from unilateral brain lesions in children. In S. H. Broman \& J. M. Fletcher (Eds.), The changing nervous system (pp. 254-273). New York: Oxford University Press.

Aram, D., \& Eisele, J. (1992). Plasticity and recovery of higher cortical functions following early brain injury. In I. Rapin \& S. J. Segalowitz (Eds.), Handbook of neuropsychology: Child neuropsychology. New York: American Elsevier.

Bates, E. (1999). Plasticity, localization and language development. In S. H. Broman \& J. M. Fletcher (Eds.), The Changing Nervous System (pp. 214-253). New York: Oxford University Press 
Bates, E., Thal, D., \& Janowsky, J. (1992). Early language correlates and its neural correlates. In I. Rapin \& S. Segalowitz (Eds.). Handbook of neuropsychology: Child neurology (Vol. 6). Amsterdam: Elsevier.

Bates, E., Vicari, S., \& Trauner, D. (1999). Neural mediation of language development: Perspectives from lesion studies of infants and children. In H. Tager-Flusberg (Ed.), Neurodevelopmental Disorders (pp. 533-582). Cambridge, MA: MIT Press.

Binder, J., \& Price, C. (2001). Functional imaging of language. In R. Cabezo \& A. Kingstone (Eds.), Neuroimaging of cognition (pp. 187-251). Cambridge, MA: MIT Press.

Blake, M. (2003). Affective language and humor appreciation after right hemisphere brain damage. Seminars in Speech Language, 24, 107-120.

Boatman, D., Freeman, J., Vining, E., Pulsifer, M., Miglioretti, D., Minahan, R., Carson, B., Brandt, J., \& McKhann, G. (1999). Language recovery after left hemispherectomy in children with late-onset seizures. Annals of Neurology, 46(4), 579-586.

Bock, K. (1991). A sketchbook of production problems. Journal of Psycholinguistic Research, 20(3), 141-160.

Borer, H. (1984). Parametric syntax. Dordrecht, The Netherlands: Foris.

Borer, H., \& Rohrbacher, B. (2003). Minding the absent: Arguments for the Full Competence hypothesis. Language Acquisition, 10(2), 123-176.

Brownell, H., Michel, D., Powelson, J., \& Garndern, H. (1983). Surprise but not coherence: Sensitivity to verbal humor in right-hemisphere patients. Brain and Language, 18, 20-27.

Campbell, R. (1991). Tense and agreement in different tenses. The Linguistic Review, 8(2-4), 159-184.

Caplan, D. (2000). Positron emission tomographic studies of syntactic processing. In Y. Grodzinsky, L. Shapiro, \& D. Swinney (Eds.), Language and the brain: Representation and processing (pp. 316325).

Caplan, R., Guthrie, D., Fish, B., Tanguay, P. E., \& David-Lando, G. (1989). The Kiddie Formal Thought Disorder rating Scale, (KFTDS). Clinical assessment, reliability, and validity. Journal of the American Academy of Child and Adolescent Psychiatry, 28, 208216.

Caplan, R., Guthrie, D., Shields, W. D., Peacock, W. J., Vinters, H., \& Yudovin, S. (1993). Communication deficits in children undergoing temporal lobectomy. Journal of American Academy of Child and Adolescent Psychiatry, 32, 604-611.

Chomsky, N. (1981). Lectures on Government and Binding. Dordrecht: Foris.

Chomsky, N. (1991). Some notes on economy of derivation and representation. In R. Freidin (Ed.), Principles and Parameters in comparative grammar. Cambridge, MA: MIT Press.

Chomsky, N. (1995). The Minimalist Program. Cambridge, MA: MIT Press.

Chomsky, N. (2000). Minimalist inquiries: The framework. In R. Martin, D. Michaels, \& J. Uriagereka (Eds.), Step by step: Essays on minimalist syntax in honor of Howard Lasnik. Cambridge, MA: MIT Press.

Cohen, M. (1992). Auditory/verbal and visual/spatial memory in children with complex partial epilepsy of temporal lobe origin. Brain and Language, 20, 315-326.

Cook, S. W., Nguyen, S. T., Hu, B., Yudovin, S., Shields, W. D., Vinters, H. V., et al. (2004). Cerebral hemispherectomy for pediatric epilepsy patients: A comparison of three techniques by pathologic substrate in 115 patients. Journal of Neurosurgery, submitted.

Coulson, S. (in press). Right hemisphere activation of joke-related information: An event-related brain potential study. Journal of Cognitive Neuroscience.
Curtiss, S. \& de Bode, S. (1998). Linguistic outcomes for hemispherectomized children. In Proceedings of the 22nd Annual Boston University Conference on Language Development, Cascadilla Press.

Curtiss, S., \& de Bode, S. (1999). Age and etiology as predictors of language outcome following hemispherectomy. Developmental Neuroscience, 21, 174-181.

Curtiss, S., \& de Bode, S. (2003). How normal is grammatical development in the right hemisphere following hemispherectomy? The RI stage and beyond. Brain and Language, 86, 193-206.

Curtiss, S., de Bode, S., \& Mathern, G. W. (2001). Spoken language outcomes after hemispherectomy: Factoring in etiology. Brain and Language, 79, 379-396.

Curtiss, S., MacSwan, J., Schaeffer, J., Kural, M., \& Sano, T. (2004). GCS: A grammatical coding system for natural language data. Behavior Research Methods, Instruments, and Computers, 36(3), 459-488.

Curtiss, S., \& Schaeffer, J. (1997). Development of the I- and D-system in children with hemispherectomy. Paper presented at the Fourth Annual Society for Cognitive Neuroscience.

Day, P., \& Ulatowska, H. (1979). Perceptual, cognitive, and linguistic development after early hemispherectomy: two case studies. Brain and Language, 7, 17-33.

Dennis, M. (1980a). Capacity and strategy for syntactic comprehension after left or right hemidecortication. Brain and Language, 10, 287-317.

Dennis, M. (1980b). Language acquisition in a single hemisphere: semantic organization. In D. Caplan (Ed.), Biological studies of mental processes (pp. 159-185). Cambridge, MA: MIT Press.

Dennis, M., \& Kohn, B. (1975). Comprehension of syntax in infantile hemiplegics after cerebral hemidecortication: Left hemisphere superiority. Brain and Language, 2(4), 472-482.

Dennis, M., \& Whitaker, H. (1976). Language acquisition following hemidecortication: Linguistic superiority of the left over the right hemisphere. Brain and Language, 3, 404-433.

Fox, D., \& Pesetsky, D. (2003). Cyclic linearization and the typology of movement. Paper presented at GLOW, 2003.

Gallagher, T., \& Watkin, K. (1997). 3D ultrasonic fetal neuroimaging and familial language disorder. Journal of Neurolinguistics, 10(2/3), $187-211$.

Guilfoyle, E., \& Noonan, M. (1989). Functional Categories and language acquisition. Unpublished Ms. McGill University.

Hamann, C. (1996). Null-arguments in German child language. Language Acquisition, 5(3), 155-208.

Harris, T., \& Wexler, K. (1996). The optional-infinitive stage in child English. Evidence from negation. In H. S. Clahsen (Ed.), Generative Perspectives in Language Acquisition (pp. 1-42).

Hickok, G. (2000). Speech perception, conduction aphasia, and the functional neuroanatomy of language. In Y. Grodzinsky, L. Shapiro, \& D. Swinney (Eds.), Language and the brain: Representation and processing (pp. 87-104).

Hickok, G., Love-Geffen, T., \& Klima, E. (2002). Role of the left hemisphere in sign language comprehension. Brain and Language, 82(2), 167-178.

Hoekstra, T., \& Hyams, N. (1998). Aspects of root infinitives. Lingua, $106,81-112$.

Hulk, A., \& Mueller, N. (2000). Bilingual first language acquisition at the interface between syntax and pragmatics. Bilingualism: Language and Cognition, 3(3), 227-244.

Hyams, N. (1992). A reanalysis of null subjects in child language. In J. Weissenborn, H. Goodluck, \& T. Roeper (Eds.), Theoretical issues in language acquisition. Hillsdale, $\mathrm{NJ}$ : Lawrence Erlbaum.

Hyams, N. (1996). The underspecifications of functional categories in early grammars. In H. S. Clahsen (Ed.), Generative perspectives 
on language acquisition (14, pp. 91-127). Amsterdam: John Benjamins.

Hyams, N. (1999). Underspecification and modularity in early syntax. A formalist perspective. In M. Darnell, E. Moravcsik, F. Newmeyer, M. Noonan, \& K. Wheatley (Eds.), Functionalism and formalism in linguistics (pp. 387-413). Amsterdam/Philadelphia: John Benjamins.

Hyams, N. (2001). Now you hear it, now you don't: The nature of optionality in child grammars. In Proceedings of the 25th annual Boston University conference on language development (pp. 34-58). Somerville, MA: Cascadilla Press.

Johnson, K. (1986). The syntax of inflectional paradigms. Unpublished ms. University of Wisconsin, Madison.

Jonas, R., Nguyen, S., Hu, B., Asarnow, R., LoPresti, C., Curtiss, S., et al. (2004). Predictors of hospital course, seizure, developmental, language and motor outcomes after cerebral hemispherectomy in children. Neurology.

Lebeaux, D. (1988). The feature +affected and the formation of the passive. In W. Wilkins (Ed.), Thematic relations: Syntax and semantics. New York: Academic Press.

Lenneberg, E. (1967). The biological foundations of language. New York: Academic Press.

Locke, J. L. (1997). A theory of neurolinguistic development. Brain and Language, 58, 265-326.

Longobardi, G. (1994). Reference and proper names: A theory of Nmovement in syntax and logical form. Linguistic Inquiry, 25, 609-665.

MacWhinney, B., \& Snow, K. (1985). The child language data exchange system. Journal of Child Language, 12, 271296.

MacWhinney, B., \& Snow, K. (1990). The child language data exchange system. Journal of Child Language, 17, 457-472.

Mariotti, P., Iuvone, L., Torrioli, M. G., \& Silveri, M. C. (1998). Linguistic and non-linguistic abilities in a patient with early left hemispherectomy. Neuropsychologia, 36(12), 1303-1312.

Mills, D., Coffey-Corina, S., \& Neville, H. (1994). Language comprehension and cerebral specialization from 13 to 20 months. Developmental Neuropsychology, 13(3), 397-445.

Molfese, D. (1990). Auditory evoked responses recorded from 16month-old human infants to words they did and did not know. Brain and Language, 38, 345-363.

Molfese, D., \& Molfese, V. (1986). Psycophysical indices of early cognitive processes and their relationship to language. In J. Obrzuit \& G. Hynd (Eds.), Child neuropsychology: Vol. 1. Theory and research. New York: Academic Press.

Molfese, D., \& Segalowitz, S. (1988). Brain lateralization in children. New York: The Guilford Press.

Newport, E. (1988). Constraints on learning and their role in language acquisition: Studies of the acquisition of American Sign Language. Language Science, 10, 147-172.

Ogden, J. A. (1988). Language and memory functions after long recovery periods in left-hemispherectomized subjects. Neuropsychologia, 26(5), 654-659.

Ogden, J. (1996). Phonological dyslexia and phonological dysgraphia following left and right hemispherectomy. Neuropsychologia, 34(9), 905-918.

Patterson, K., Vargha-Khadem, F., \& Polkey, C. (1989). Reading with one hemisphere. Brain, 112(1), 39-63.

Peacock, W. J., Wehby-Grant, M. C., Shields, W. D., Shewmon, D. A., Chugani, H. T., Sankar, R., et al. (1996). Hemispherectomy for intractable seizures in children: a report of 58 cases. Child's Nervous System, 12, 376-384.

Pell, M. (1999). Fundamental frequency encoding of linguistic and emotional prosody by right hemisphere-damaged speakers. Brain and Language, 69(2), 161-192.
Platzack, C. (1992). Functional categories in early Swedish. In J. Meisel (Ed.), The acquisition of verb placement. Dordrecht: Kluwer.

Platzack, C. (2001). Slips of the tongue in child language production. In N. Poulisse (Ed.), Slips of the tongue: Speech errors in first and second language production. Amsterdam/Philadelphia: John Benjamins.

Poeppel, D., \& Wexler, K. (1993). The full competence hypothesis of clause structure in early German. Language, 69, 1-33.

Pollock, J. Y. (1989). Verb movement, Universal Grammar, and the structure of IP. Linguistic Inquiry, 20, 365-424.

Poulisse, N. (1999). Slips of the tongue: Speech errors in first and second language production. Amsterdam: John Benjamins.

Radford, A. (1988). Small children's small clauses. Transactions of the Philological Society, 86, 1-46.

Radford, A. (1990). The nature of children's initial grammars of English. In L. Roca (Ed.), Logical issues in language acquisition (pp. 199-233). Foris Publications.

Radford, A. (1994). The syntax of questions in child English. Journal of Child Language, 21, 211-236.

Ritter, E. (1988). A Head-movement approach to construct state noun phrases. Linguistics, 26, 909-930.

Rizzi, L. (1997). The fine structure of the left periphery. In L. Haegeman (Ed.), Elements of grammar. Handbook in generative syntax (pp. 281-337). Dordrecht: Kluwer Academic Publishers.

Scheibel, A. (1993). Dendritic structure and language development. In B. de Boysson-Bardies et al. (Eds.), Developmental neurocognition: Speech and face processing in the first year of life. The Netherlands: Kluwer Academic Publishers.

Shammi, P., \& Stuss, D. T. (1999). Humour appreciation: A role of the right frontal lobe. Brain, 122, 657-666.

Stark, R. E., Bleile, K., Brandt, J., Freeman, J., \& Vining, E. P. (1995). Speech-language outcomes of hemispherectomy in children and young adults. Brain and Language, 51, 406-421.

Stark, R. E., \& McGregor, K. (1997). Follow-up study of a right- and a left-hemispherectomized child: Implications for localization and impairment of language in children. Brain and Language, 60, $222-242$.

Stemberger, J. (1989). Speech errors in early child language production. Journal of Memory and Language, 28, 164-188.

Thal, D. (1998). Linguistic, cognitive, and affective development in children with pre- and perinatal focal brain injury: A tenyear overview from the San Diego Longitudinal Project. In Advances in Infancy Research (pp. 131-163). Norwood, NJ: Ablex.

Vargha-Khadem, F., Carr, L. J., Isaacs, E., Brett, E., Adams, C., \& Mishkin, M. (1997). Onset of speech after left hemispherectomy in a nine-year-old boy. Brain, 120, 159-182.

Vargha-Khadem, F., \& Mishkin, M. (1997). Speech and language outcome after hemispherectomy in childhood. In I. Tuxhorn, H. Holthausen, \& H. Boenigk (Eds.), Paediatric epilepsy syndromes and their surgical treatment (pp. 774-784). London: John Libbey.

Vargha-Khadem, F., \& Polkey, C. E. (1992). Review of cognitive outcome after hemidecortication in humans. In F. D. Rose \& D. A. Johnson (Eds.), Recovery from brain damage (pp. 137-151). New York: Plenum Press.

Verity, C. M., Strauss, E. H., Moyes, P. D., Wada, J. A., Dunn, H. G., \& Lapointe, J. S. (1982). Long-term follow-up after cerebral hemispherectomy: neurophysiologic, radiologic, and psychological findings. Neurology, 32, 629-639.

Verrips, M., \& Weissenborn, J. (1992). Routes to verb placement in early German and French: The independence of finiteness and agreement. In J. Meisel (Ed.), The acquisition of verb placement. Dordrecht: Klower. 
Wilson, S. (2003). Lexically specific constructions in the acquisition of inflection in English. Journal of Child Language, 30(no. 1), $75-115$.
Witelson, S. (1982). Bumps on the brain. Right-left anatomic asymmetry as a key to functional lateralization. In Language functions and brain organization (pp. 117-144). New York: Academic Press. 